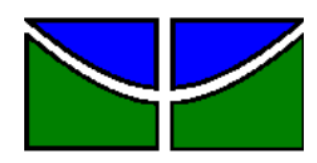

UNIVERSIDADE DE BRASÍLIA

Faculdade de Educação - UAB/UnB/MEC/SECAD

Curso de Especialização em Educação na Diversidade e Cidadania, com Ênfase em EJA

MARIA DE LURDES FRANCISCA DOS SANTOS

MARTHA EMÍLIA DE OLIVEIRA E CASTRO

EDUCAÇÃO A DISTÂNCIA EM EJA: UMA ESTRATÉGIA DE PERMANÊNCIA E CONCLUSÃO DO ENSINO MÉDIO

BRASÍLIA- DF

JUNHO/2010 
UNIVERSIDADE DE BRASÍLIA

Faculdade de Educação - UAB/UnB/MEC/SECAD

Curso de Especialização em Educação na Diversidade e

Cidadania, com Ênfase em EJA

\title{
EDUCAÇÃO A DISTÂNCIA EM EJA: UMA ESTRATÉGIA DE PERMANÊNCIA E CONCLUSÃO DO ENSINO MÉDIO
}

\author{
MARIA DE LURDES FRANCISCA DOS SANTOS \\ MARTHA EMÍLIA DE OLIVEIRA E CASTRO
}

MARIA LUIZA PEREIRA ANGELIM

MARIA DO SOCORRO DA SILVA LINHARES

CATARINA ALMEIDA DOS SANTOS

PROJETO DE INTERVENÇÃO 
BRASÍLIA, DF JUNHO/2010

UNIVERSIDADE DE BRASÍLIA

Faculdade de Educação - UAB/UnB/MEC/SECAD

Curso de Especialização em Educação na Diversidade e

Cidadania, com Ênfase em EJA

MARIA DE LURDES FRANCISCA DOS SANTOS

MARTHA EMÍLIA DE OLIVEIRA E CASTRO

\section{EDUCAÇÃO A DISTÂNCIA EM EJA: UMA ESTRATÉGIA DE PERMANÊNCIA E CONCLUSÃO DO ENSINO MÉDIO}

Trabalho de conclusão do Curso de Especialização em Educação na Diversidade e Cidadania, com Ênfase em EJA, como parte dos requisitos necessários para obtenção do grau de Especialista em Educação de Jovens e Adultos

Maria Luiza Pereira Angelim

Maria do Socorro da Silva Linhares

Catarina Almeida dos Santos

BRASÍLIA, DF JUNHO/2010 


\section{RESUMO}

No Distrito Federal a Educação de Jovens e Adultos (EJA) é oferecida a todo cidadão que queira concluir o ensino fundamental e/ou médio em um período mais curto do que o convencional. Contudo o ingresso desses alunos nessa modalidade de ensino não tem garantido a conclusão no prazo estimado. No início do semestre as salas estão cheias de educandos, mas no decorrer do tempo vão esvaziando. Este fenômeno, caracterizado como evasão escolar, atinge todo o Brasil. No Distrito Federal o índice de evasão é de 32\%, conforme dados do IBGE de 2009. Assim como ocorre em todo o DF, a evasão escolar também acontece no Centro Educacional 07 de Ceilândia - DF, com índice de 46\% em 2009, em virtude dos alunos serem trabalhadores/as e/ou donos/as de casa, enfrentando dupla jornada de trabalho e, ainda, por não conseguirem conciliar o horário do trabalho com o da escola. Desta forma, procurando soluções para conter a evasão na EJA - Ensino Médio, propomos, como Política Pública a Educação a Distância para esta modalidade a ser implementada, de forma experimental no CED 07 de Ceilândia do Distrito Federal, por entendermos que esta forma de ensino é a mais adequada para atender à demanda de estudantes que buscam a escolarização e não conseguem conciliar seus afazeres com as necessidades escolares. Como proposta de implementação do sistema à distância para a educação de jovens e adultos, tomamos a Resolução № 3, de 15 de junho de 2010 do Conselho Nacional Educação / Câmara de Educação Básica, como parâmetro para a execução deste projeto que institui as Diretrizes Operacionais para a Educação de Jovens e Adultos. Pretende-se a execução do projeto no decorrer do semestre letivo de 2010 e terá como desafio a conquista de parceiros que somem esforços para a sua realização e implementação, como a Escola de Aperfeiçoamento de Professores (EAPE), o Programa Universidade Aberta do Brasil (UAB) e a Universidade de Brasília.

Palavras-chave: Educação a distância, Educação de jovens e Adultos, Evasão, Permanência. 


\section{LISTA DE FIGURAS}

Figura 1. Localização do CED 07 de Ceilândia-DF, através do recurso Google Earth 09

Figura 2: Carlos Henrique (nome fictício), motorista, aluno do $3^{\circ}$ ano. Imagem autorizada ..... 18

Figura 3: Bruno Santos (Nome fictício), aluno do $3^{\circ}$ ano. Imagem autorizada ..... 18 


\section{LISTA DE TABELAS}

Tabela 1 - $3^{\circ}$ Segmento da EJA - CED 07 de Ceilândia ........................................................ 10

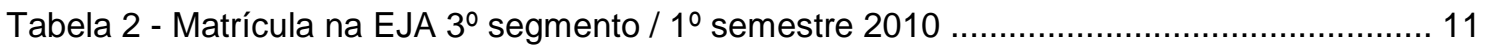

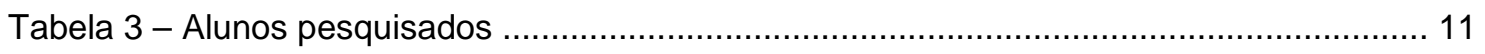

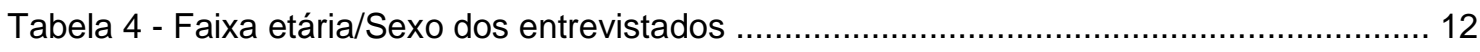

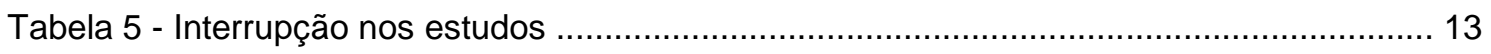

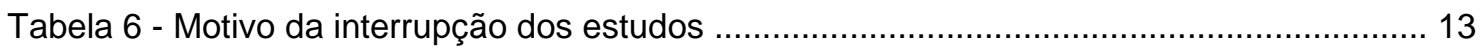

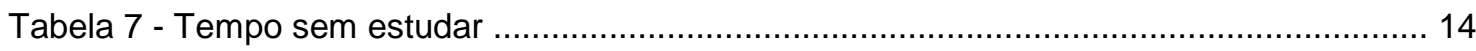

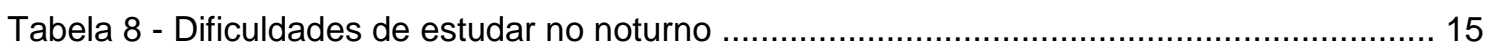

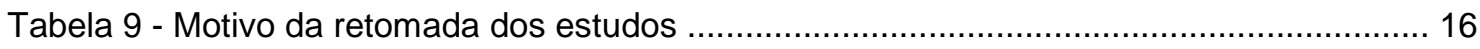

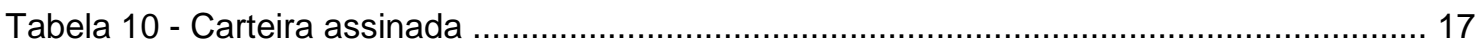

Tabela 11 - Renda como principal sustento do domicílio ……............................................... 19

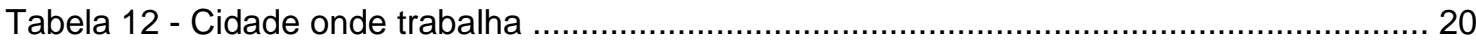

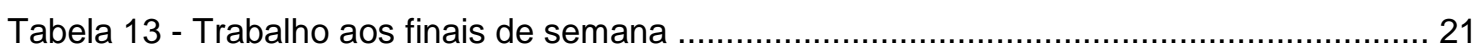

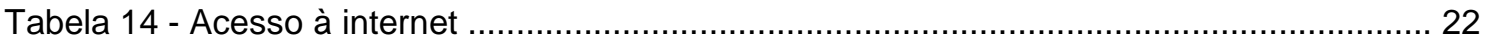

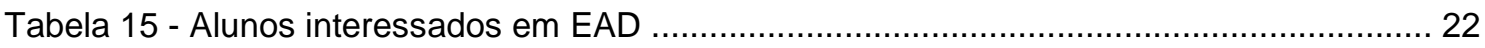

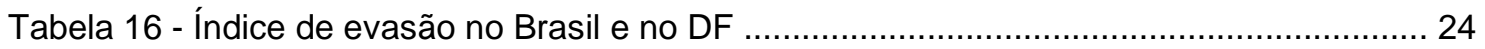

Tabela 17 - Indicadores de rendimento da EJA no CED 07 de Ceilândia - DF - $3^{\circ}$ segmento 24 


\section{LISTA DE GRÁFCOS}

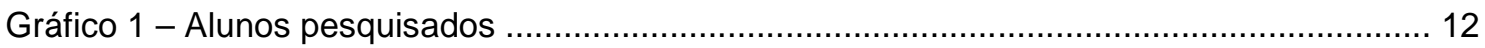

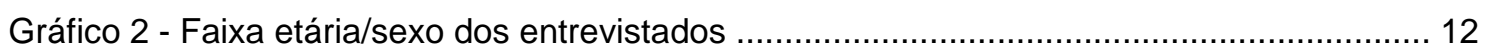

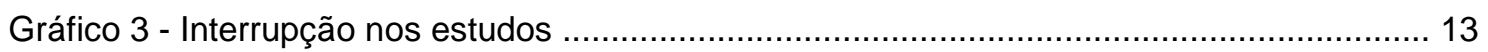

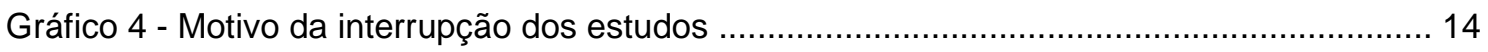

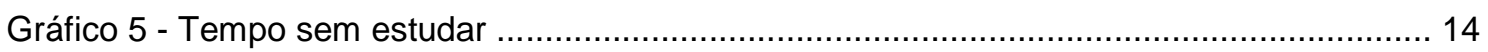

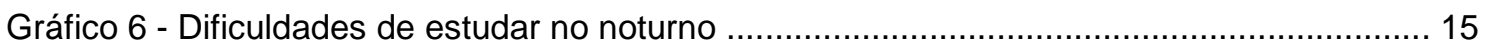

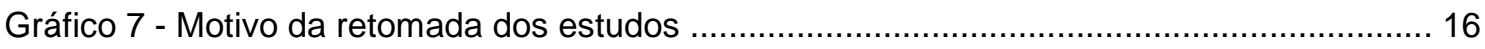

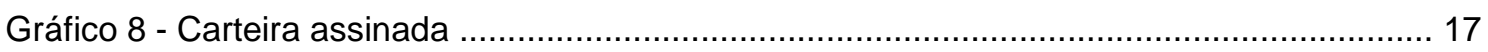

Gráfico 9 - Renda como principal sustento do domicílio ...................................................... 19

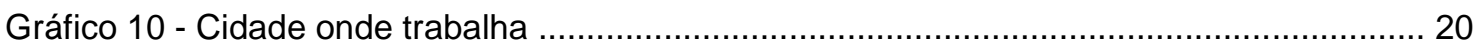

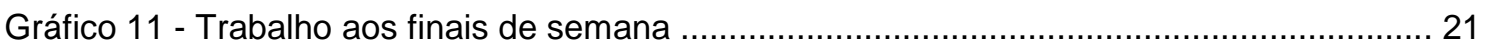

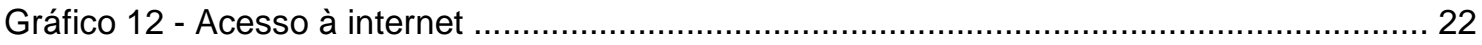

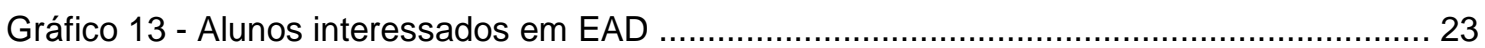




\section{SUMÁRIO}

DADOS DE IDENTIFICAÇÃO DOS PROPONENTES …............................... 09

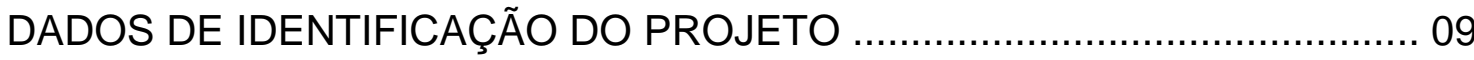

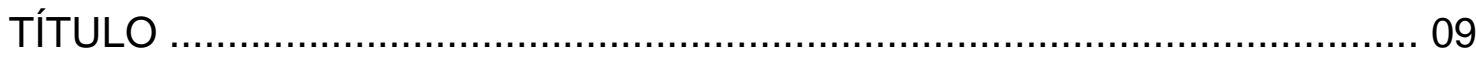

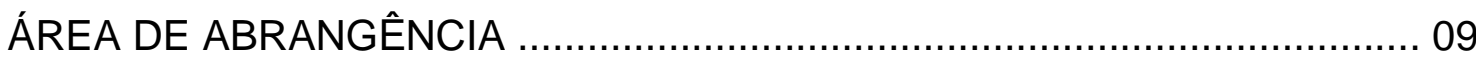

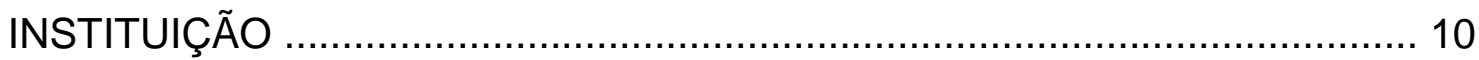

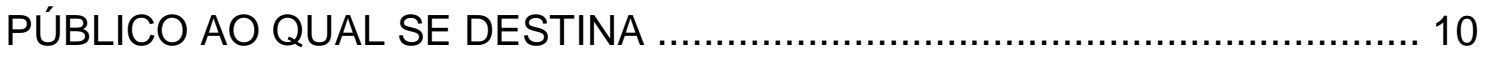

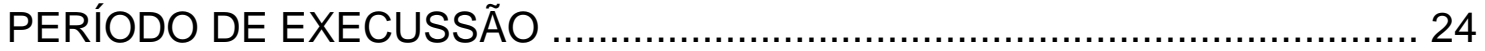

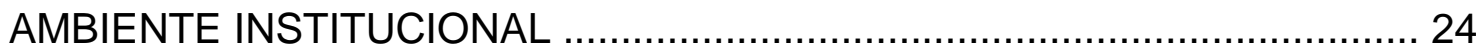

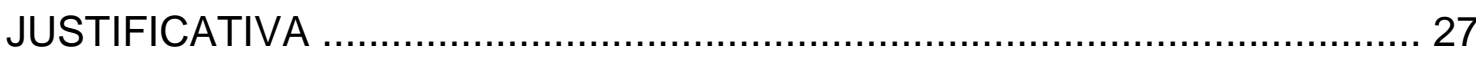

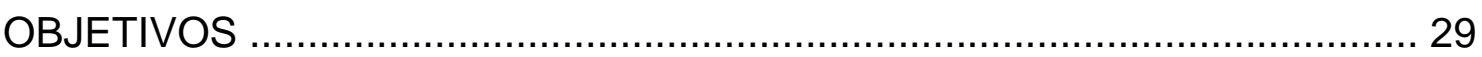

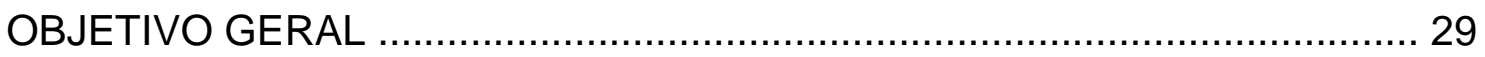

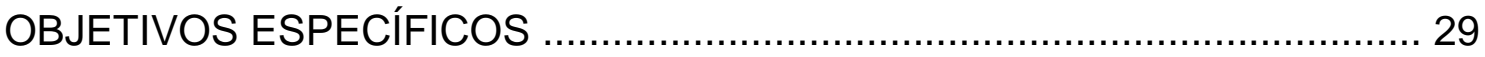

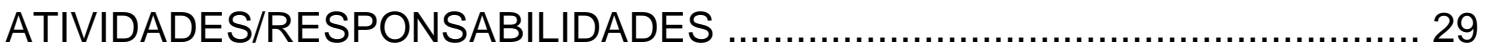

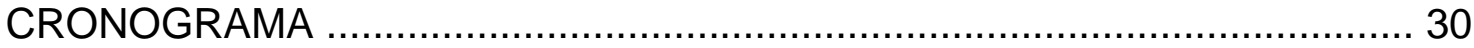

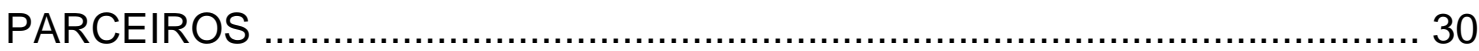

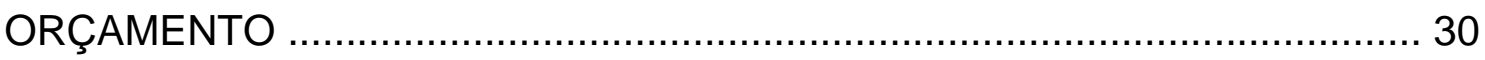

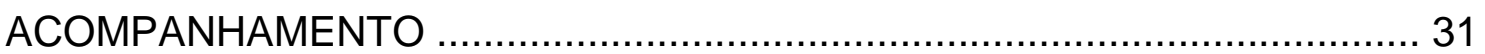

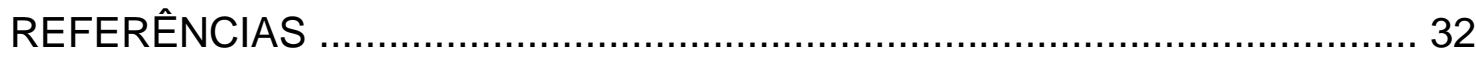

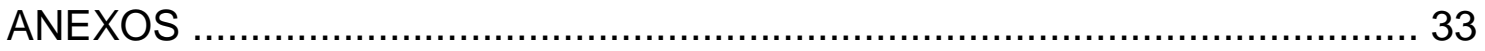




\section{DADOS DE IDENTIFICAÇÃO DOS PROPONENTES}

1. 1 - Maria de Lurdes F. dos Santos

1.1.1 - Martha Emilia de Oliveira e Castro

1.2- Turma "C"

1.3 - Telefone (61) 35853060/92025846 e-mail: Isantos.filosofia@gmail.com

1.3.1 - telefone (61) 34711313 / 81115671 e-mail: marthaemilia@terra.com.br

\section{2 - DADOS DE IDENTIFICAÇÃO DO PROJETO}

\subsection{Título}

Educação a distância em EJA: Uma estratégia de permanência e conclusão do Ensino Médio.

\section{2 Área de abrangência}

O referido Projeto terá como público alvo os alunos matriculados no Centro Educacional 07 de Ceilândia, na Região Administrativa de Ceilândia, Distrito Federal. Localizado à QNN 13, Área Especial, o CED 07 recebe alunos, em sua maioria, moradores de regiões próximas à escola: Ceilândia Oeste, Ceilândia Leste, Ceilândia Centro, "P" Norte, Setor "O", Setor "Q", Setor "R" e Condomínio Privê.

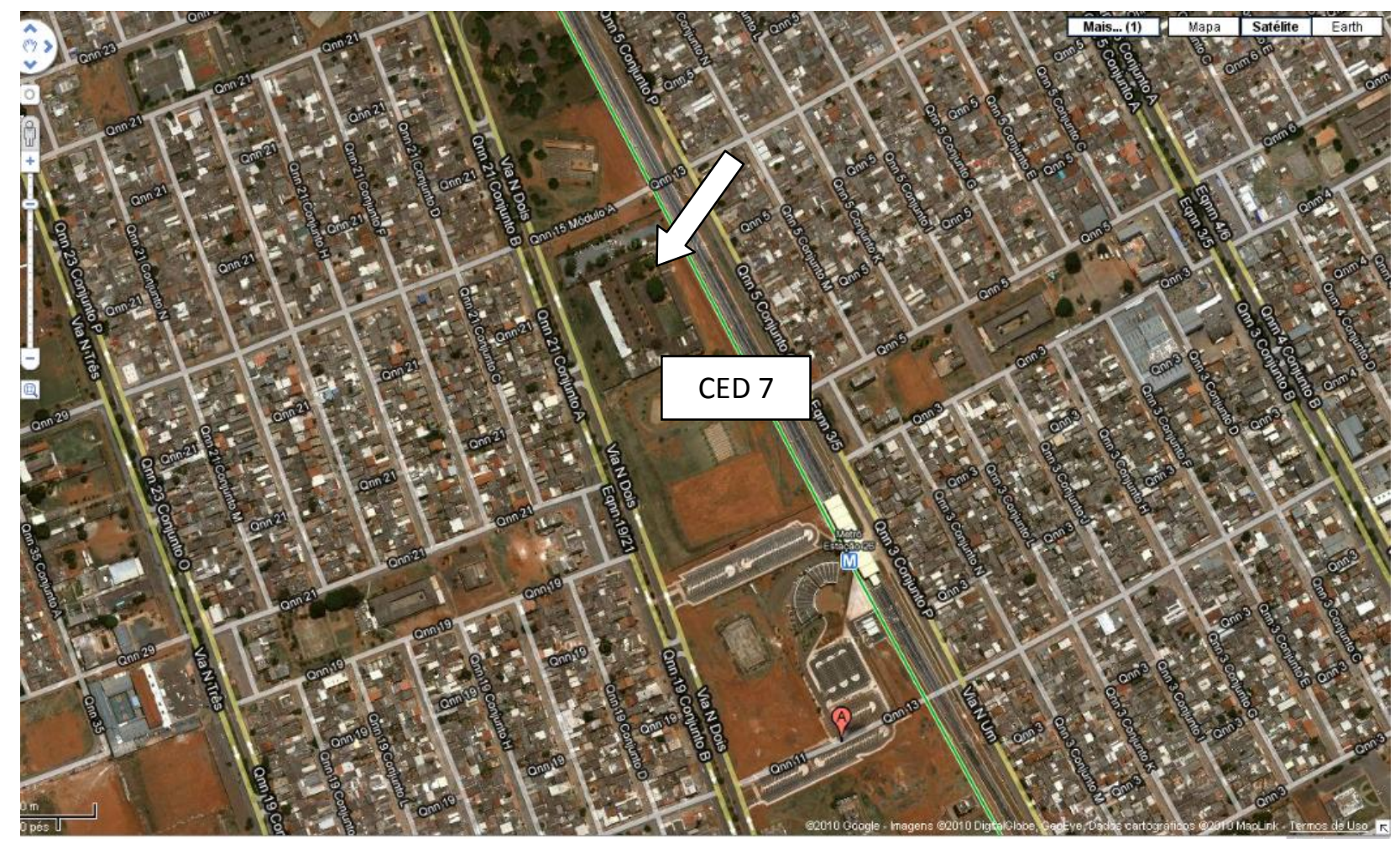

Figura 1. Localização do CED 07 de Ceilândia-DF, através do recurso Google Earth 


\subsection{Instituição}

Centro Educacional 07 de Ceilândia, situado à QNN 13, Área Especial, Ceilândia Oeste, Distrito Federal.

Governo do Distrito Federal

Secretaria de Estado de Educação do DF

Diretoria Regional de Ensino de Ceilândia, DF

\subsection{Público ao qual se destina}

O projeto destina-se a alunos da EJA do $3^{\circ}$ segmento, matriculados no CED 07 de Ceilândia, no Distrito Federal, como proposta à fomentação de uma Política Pública voltada para a EJA no DF. De acordo com o Projeto Político Pedagógico da escola, o CED 07 atende alunos do Ensino Fundamental (séries finais) e médio em três turnos. Especificamente no turno noturno, o CED 07 destina suas atividades para os alunos matriculados na EJA, $3^{\circ}$ segmento, nas três séries. Conforme a estratégia de matrícula a cada semestre, o número de turmas variam. Neste $1^{\circ}$ semestre de 2010 , temos 4 turmas de $1^{\circ}$ ano, 4 de $2^{\circ}$ e 4 de $3^{\circ}$, totalizando 12 turmas do $3^{\circ}$ segmento. Em sua grande maioria, os alunos matriculados nesta modalidade são adultos, trabalhadores, que vem à escola interessados em concluir o ensino médio, motivados por interesses diversos como recuperar o tempo perdido, promover-se no emprego, fazer faculdade e como fator de realização pessoal. Ainda de acordo com o Projeto Político Pedagógico (PPP), muitos desses estudantes não conseguem conciliar escola e trabalho, o que leva a um número de matriculados a cada semestre e a outro número considerável de evasão desses mesmos estudantes ao final de cada semestre. Segundo dados da Secretaria da Escola, através da Movimentação e Rendimento Escolar para EJA podemos observar, conforme tabela 1, a seguir, a movimentação ao final do $2^{\circ}$ semestre de 2009 :

Tabela 1

$3^{\circ}$ Segmento da EJA - CED 07 de Ceilândia

\begin{tabular}{|c|c|c|c|c|c|c|}
\hline \multicolumn{2}{|c|}{ Movimentação } & $1^{\circ}$ Ano & $2^{\circ}$ Ano & $3^{\circ}$ Ano & Total & $\begin{array}{l}\text { Total } \\
\text { em } \%\end{array}$ \\
\hline \multicolumn{2}{|c|}{$\begin{array}{l}\text { Matrícula inicial em } \\
27 / 05 / 2009\end{array}$} & 187 & 133 & 221 & 541 & - \\
\hline \multicolumn{2}{|c|}{$\begin{array}{l}\text { Admitidos após } \\
27 / 05 / 2009\end{array}$} & 05 & 04 & 04 & 13 & - \\
\hline \multicolumn{2}{|c|}{$\begin{array}{l}\text { Afastados por } \\
\text { transferência }\end{array}$} & - & - & - & - & - \\
\hline \multicolumn{2}{|c|}{ Matrícula final } & 192 & 137 & 225 & 554 & 100,00 \\
\hline \multirow{3}{*}{ 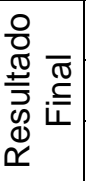 } & Aptos(A) & 101 & 79 & 116 & 296 & 53,42 \\
\hline & Não aptos(NA) & 17 & 20 & 40 & 77 & 13,90 \\
\hline & Abandono(ABA) & 74 & 38 & 69 & 181 & 32,67 \\
\hline
\end{tabular}

Fonte: SOME Ced 07 de Ceilândia - DF/2010 
Conforme informação prestada em maio deste ano pela secretaria do CED 07, (visto que a Movimentação e Rendimento Escolar para EJA estará disponível apenas ao final do semestre de 2010), temos os seguintes dados:

Tabela 2

Matrícula na EJA $3^{\circ}$ segmento $/ 1^{\circ}$ semestre 2010

\begin{tabular}{c|c|c|c|c|c|c|c}
\hline $\begin{array}{c}\text { Matrícula } \\
\text { inicial }\end{array}$ & $\begin{array}{c}\mathrm{N}^{\circ} \text { de } \\
\text { Turmas }\end{array}$ & Desistentes & $\%$ & Infrequentes & $\%$ & $\begin{array}{c}\text { Total de } \\
\text { alunos em } \\
\text { maio/2010 }\end{array}$ & $\begin{array}{c}\% \text { total de } \\
\text { abandono }\end{array}$ \\
\hline 650 & 12 & 128 & 19,69 & 133 & 20,47 & 389 & 40,15 \\
\hline
\end{tabular}

Fonte: Informações da Secretaria do CED 07 Ceilândia - DF/2010

Comparando-se as duas primeiras tabelas (tabela 1 e 2), podemos notar que o total de alunos matriculados para o $2^{\circ}$ semestre letivo de 2009 é menor que o número de alunos para o $1^{\circ}$ semestre de 2010. Percebemos também que a taxa de abandono em 2009 (considerando-se o somatório entre NA e ABA) representam pouco mais de $46 \%$ e que em maio de 2010 a taxa já é superior a 40\%.

Em pesquisa realizada através da disciplina de Filosofia, por meio da aplicação arbitrária de questionário fechado adaptado do questionário do Professor Nelson Moreira Sobrinho e da Professora Sandra Amélia Cardoso, ambos do Centro Educacional 11 de Ceilândia - DF e alunos do presente curso, para um grupo composto de 157 alunos do $3^{\circ}$ segmento, distribuídos nas três séries no início do semestre de 2010, obtivemos resultados com a quantificação e análise dos dados. A aplicação dos questionários, ocorrida no início de abril de 2010, momento em que a EJA do CED 07 de Ceilândia - DF, tinha cerca de 450 alunos, pretendia-se uma abrangência de 50\% dos alunos matriculados neste período, sendo 2 turmas de cada série, o que levaria a cerca de 225 alunos pesquisados. No entanto, na aplicação obtivemos 157 questionários devolvidos e respondidos, visto que no dia, era este o número de alunos presentes. A representação dos dados são mostrados a seguir:

Tabela 3

Alunos pesquisados

\begin{tabular}{c|c|c|c}
\hline & Total de entrevistados & Homens & Mulheres \\
\hline $\mathrm{N}^{\mathrm{o}}$ & 157 & 68 & 89 \\
\hline$\%$ & 100,00 & 43,32 & 56,68 \\
\hline
\end{tabular}

Fonte: dados da pesquisa de campo - CED 07 de Ceilândia - DF/2010

Dos 157 entrevistados, 68 são homens, representando 43,32\% e 89 são mulheres o que representam $56,68 \%$. Vemos, assim, que o maior número de entrevistados neste grupo da EJA no CED 07 de Ceilândia - DF é do público feminino. 


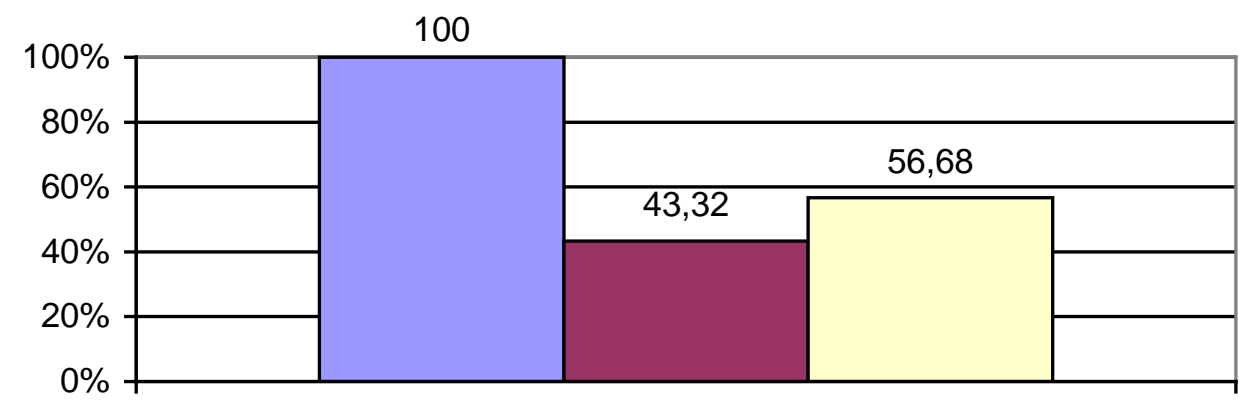

Composição da pesquisa

口Total $\square$ Homens aMulheres

Gráfico 1 - Alunos pesquisados

Fonte: dados da pesquisa de campo - CED 07 de Ceilândia - DF/2010

Em relação à faixa etária/sexo desses alunos, obtivemos a seguinte informação:

Tabela 4

Faixa etária/Sexo dos entrevistados

\begin{tabular}{|c|c|c|c|c|c|c|c|c|c|c|}
\hline & \multicolumn{2}{|c|}{$\begin{array}{c}17 \text { a } 24 \\
\text { anos }\end{array}$} & \multicolumn{2}{|c|}{$\begin{array}{c}25 \text { a } 32 \\
\text { anos }\end{array}$} & \multicolumn{2}{|c|}{$\begin{array}{c}33 \text { a } 40 \\
\text { anos }\end{array}$} & \multicolumn{2}{|c|}{$\begin{array}{c}41 \text { a } 48 \\
\text { anos }\end{array}$} & \multicolumn{2}{|c|}{$\begin{array}{l}49 \text { anos ou } \\
\text { mais }\end{array}$} \\
\hline & $\mathrm{N}^{\mathrm{O}}$ & $\%$ & $\mathrm{~N}^{\circ}$ & $\%$ & $\mathrm{~N}^{\mathrm{O}}$ & $\%$ & $\mathrm{~N}^{\circ}$ & $\%$ & $\mathrm{~N}^{\mathrm{O}}$ & $\%$ \\
\hline Total & 90 & 57,32 & 41 & 26,12 & 20 & 12,74 & 5 & 3,18 & 1 & 0,64 \\
\hline Homens & 43 & 47,78 & 16 & 39,02 & 7 & 35,00 & 2 & 40,00 & 0 & 0,00 \\
\hline Mulheres & 47 & 52,22 & 25 & 60,98 & 13 & 65,00 & 3 & 60,00 & 1 & 100,00 \\
\hline
\end{tabular}

Fonte: dados da pesquisa de campo - CED 07 de Ceilândia - DF/2010

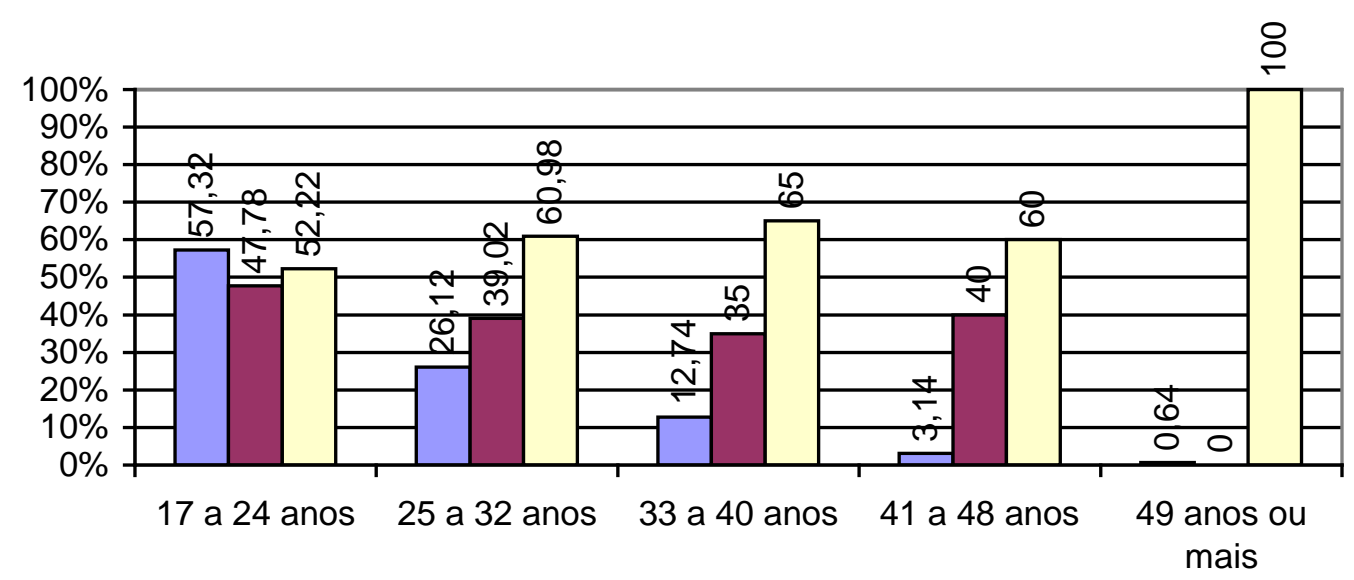

$\square$ Total $\square$ Homens $\square$ Mulheres

Gráfico 2 - Faixa etária/Sexo dos entrevistados

Fonte: dados da pesquisa 
Notamos, com isso, que a maioria dos entrevistados se encontra na faixa de 17 a 24 anos, o que mostra uma tendência à crescente juvenilização dos alunos da EJA. Vemos ainda que entre homens e mulheres, são elas as o maior número em cada faixa etária.

No que diz respeito à interrupção nos estudos, temos:

Tabela 5

Interrupção nos estudos

\begin{tabular}{c|r|r|r|r|r|r}
\hline & \multicolumn{2}{|c|}{ Sim } & \multicolumn{2}{c|}{ Não } & \multicolumn{2}{c}{ Não respondeu } \\
\cline { 2 - 7 } & \multicolumn{1}{|c|}{$\mathrm{N}^{0}$} & \multicolumn{1}{c|}{$\%$} & $\mathrm{~N}^{\mathrm{O}}$ & \multicolumn{1}{c}{$\%$} & $\mathrm{~N}^{0}$ & \multicolumn{1}{c}{$\%$} \\
\hline Total & 123 & 78,34 & 31 & 19,74 & 3 & 1,92 \\
\hline Homens & 51 & 41,46 & 16 & 51,62 & 1 & 33,34 \\
\hline Mulheres & 72 & 58,54 & 15 & 48,38 & 2 & 66,66 \\
\hline
\end{tabular}

Fonte: dados da pesquisa de campo - CED 07 de Ceilândia - DF/2010

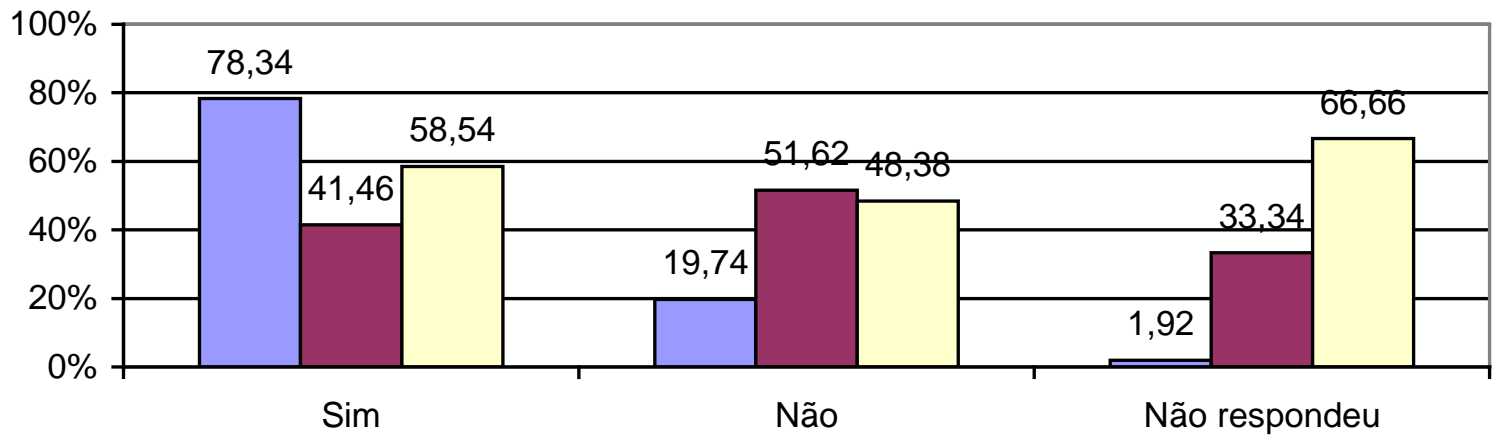

$\square$ Total $\square$ Homens $\square$ Mulheres

Gráfico 3 - Interrupção nos estudos

Fonte: dados da pesquisa de campo - CED 07 de Ceilândia - DF/2010

Grande parte de nossos alunos já interrompeu os estudos por algum tempo e motivo. Ainda aqui, vemos que a mulher passa mais tempo fora da escola. Dentre os que já interromperam os estudos, ou seja 78,34\% (123 alunos), os motivos são elencados a seguir: Tabela 6

Motivo da interrupção dos estudos

\begin{tabular}{|c|c|c|c|c|c|c|c|c|c|c|c|c|}
\hline & \multicolumn{2}{|c|}{ Família } & \multicolumn{2}{|c|}{$\begin{array}{l}\text { Falta de } \\
\text { dinheiro }\end{array}$} & \multicolumn{2}{|c|}{$\begin{array}{c}\text { Não } \\
\text { consegui } \\
\text { vaga }\end{array}$} & \multicolumn{2}{|c|}{ Trabalho } & \multicolumn{2}{|c|}{ Outros } & \multicolumn{2}{|c|}{$\begin{array}{c}\text { Não } \\
\text { respondeu }\end{array}$} \\
\hline & $\mathrm{N}^{\mathrm{O}}$ & $\%$ & $\mathrm{~N}^{\mathrm{O}}$ & $\%$ & $\mathrm{~N}^{\mathrm{O}}$ & $\%$ & $\mathrm{~N}^{\mathrm{O}}$ & $\%$ & $\mathrm{~N}^{\circ}$ & $\%$ & $\mathrm{~N}^{\mathrm{O}}$ & $\%$ \\
\hline Total & 34 & 21,65 & 4 & 2,54 & 5 & 3,18 & 62 & 39,49 & 18 & 14,64 & 34 & 21,65 \\
\hline Homens & 2 & 5,88 & 1 & 25,00 & 2 & 40,00 & 37 & 59,68 & 9 & 50,00 & 17 & 50,00 \\
\hline Mulheres & 32 & 94,12 & 3 & 75,00 & 3 & 60,00 & 25 & 40,32 & 9 & 50,00 & 17 & 50,00 \\
\hline
\end{tabular}

Fonte: dados da pesquisa de campo - CED 07 de Ceilândia - DF/2010 


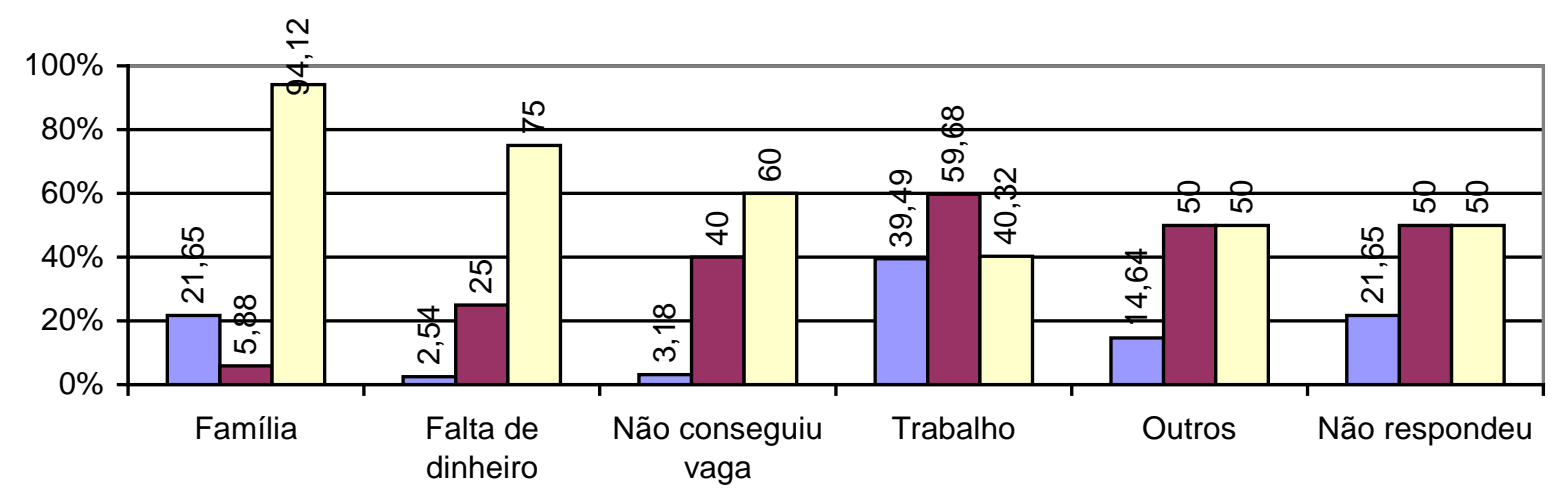

$\square$ Total $\square$ Homens $\square$ Mulheres

Gráfico 4 - Motivo da interrupção dos estudos

Fonte: dados da pesquisa de campo - CED 07 de Ceilândia - DF/2010

Neste tocante, fica evidente que o trabalho é o principal motivo da interrupção dos estudos e, dentro deste dado, tanto para o homem como para a mulher (com uma diferença de pouco mais de 19\%) este é um fator preponderante. No entanto, outro motivo da interrupção dos estudos é a família e, neste aspecto, fica evidente que para a mulher este é um fator marcante. Na opção outros motivos, temos como resposta: desinteresse $(6,5 \%)$, namoro $(0,8 \%)$, Serviço Militar Obrigatório $(0,8 \%)$ e não revelou motivo $(6,54 \%)$.

Em relação ao tempo que o aluno ficou sem estudar, temos, conforme informações abaixo:

Tabela 7

Tempo sem estudar

\begin{tabular}{|c|c|c|c|c|c|c|c|c|c|c|}
\hline & \multicolumn{2}{|c|}{ Até 1 ano } & \multicolumn{2}{|c|}{1 a 2 anos } & \multicolumn{2}{|c|}{3 a 5 anos } & \multicolumn{2}{|c|}{6 a 9 anos } & \multicolumn{2}{|c|}{$\begin{array}{c}10 \text { anos ou } \\
\text { mais }\end{array}$} \\
\hline & $\mathrm{N}^{\mathrm{O}}$ & $\%$ & $\mathrm{~N}^{\mathrm{O}}$ & $\%$ & $\mathrm{~N}^{\mathrm{O}}$ & $\%$ & $\mathrm{~N}^{\mathrm{O}}$ & $\%$ & $\mathrm{~N}^{\mathrm{O}}$ & $\%$ \\
\hline Total & 26 & 18,70 & 40 & 28,78 & 26 & 18,70 & 18 & 12,95 & 29 & 20,86 \\
\hline Homens & 10 & 38,46 & 18 & 45,00 & 13 & 50,00 & 7 & 38,88 & 7 & 24,13 \\
\hline Mulheres & 16 & 61,54 & 22 & 55,00 & 13 & 50,00 & 11 & 61,12 & 22 & 75,87 \\
\hline
\end{tabular}

Fonte: dados da pesquisa de campo - CED 07 de Ceilândia - DF/2010

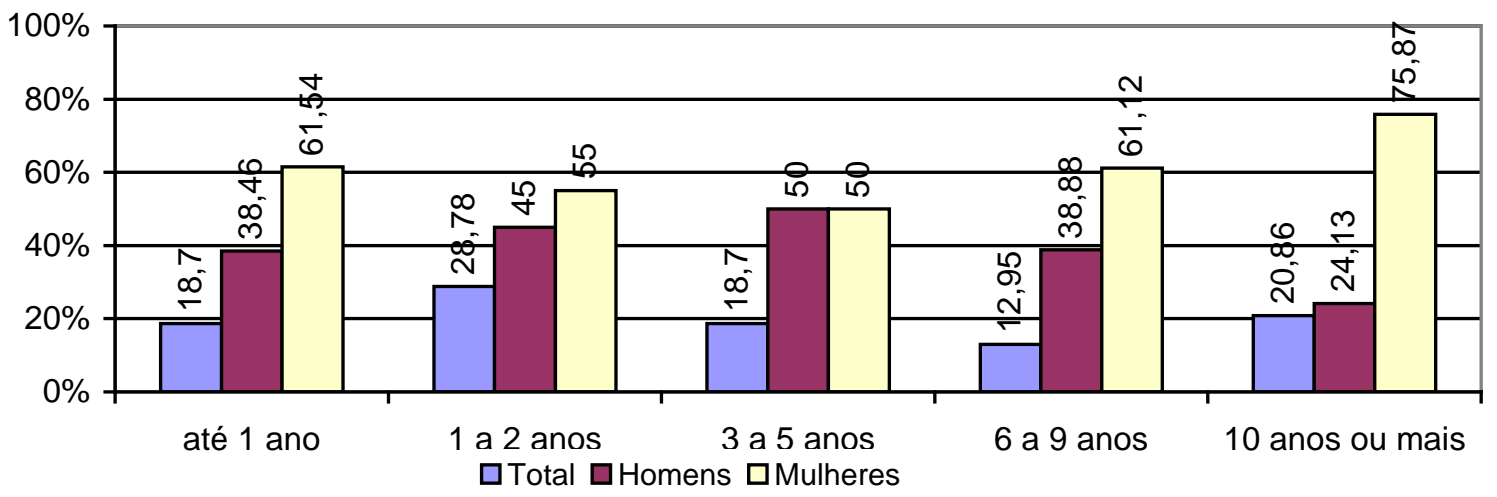

Gráfico 5 - Tempo sem estudar

Fonte: dados da pesquisa de campo - CED 07 de Ceilândia - DF/2010 
Observando os resultados do tempo que o aluno está sem estudar, podemos notar que no grupo pesquisado, 11, 46\%, ou seja, 18 alunos, não interromperam os estudos. Desses, 13 são homens (72,22\%) e 5 são mulheres (27,78\%). Os demais alunos, $88,54 \%$, ou seja 19 dos pesquisados, já ficaram algum tempo sem estudar. Cerca de aproximadamente $48 \%$ dos alunos ficou até 2 anos sem estudar. Infere-se que com a crescente matrícula de alunos cada vez mais jovens, o público da EJA passa cada vez menos tempo fora da escola. No entanto, notamos que é evidente um número considerável de alunos, pouco mais de 52\%, que ficou sem estudar de 3 a 10 anos ou mais. E ainda fica evidente, mais uma vez que é a mulher aquela que fica maior parte do tempo fora da escola.

Questionados sobre as dificuldades de se estudar à noite, os alunos responderam:

Tabela 8

\begin{tabular}{|c|c|c|c|c|c|c|c|c|c|c|}
\hline \multicolumn{11}{|c|}{ Dificuldades de estudar no noturno } \\
\hline & \multicolumn{2}{|c|}{ A } & \multicolumn{2}{|c|}{$\mathrm{B}$} & \multicolumn{2}{|c|}{$\mathrm{C}$} & \multicolumn{2}{|c|}{$\mathrm{D}$} & \multicolumn{2}{|r|}{$E$} \\
\hline & $\mathrm{N}^{\mathrm{O}}$ & $\%$ & $\mathrm{~N}^{\mathrm{O}}$ & $\%$ & $\mathrm{~N}^{\mathrm{O}}$ & $\%$ & $\mathrm{~N}^{\mathrm{O}}$ & $\%$ & $\mathrm{~N}^{\mathrm{O}}$ & $\%$ \\
\hline Total & 78 & 54,54 & 14 & 9,97 & 23 & 16,08 & 13 & 9,09 & 15 & 10,48 \\
\hline Homens & 36 & 46,15 & 7 & 50,00 & 13 & 56,52 & 0 & 0,00 & 0 & 0,00 \\
\hline Mulheres & 42 & 53,85 & 7 & 50,00 & 10 & 43,48 & 13 & 100,00 & 15 & 100,00 \\
\hline
\end{tabular}

\section{Legenda:}

A - Chegar cansado do trabalho e ainda ter que ir à escola;

B - Dificuldades com o transporte urbano;

C - O horário de trabalho incompatível com a escola;

D - Não ter com quem deixar os filhos;

E - Outros.

Fonte: dados da pesquisa de campo - CED 07 de Ceilândia - DF/2010

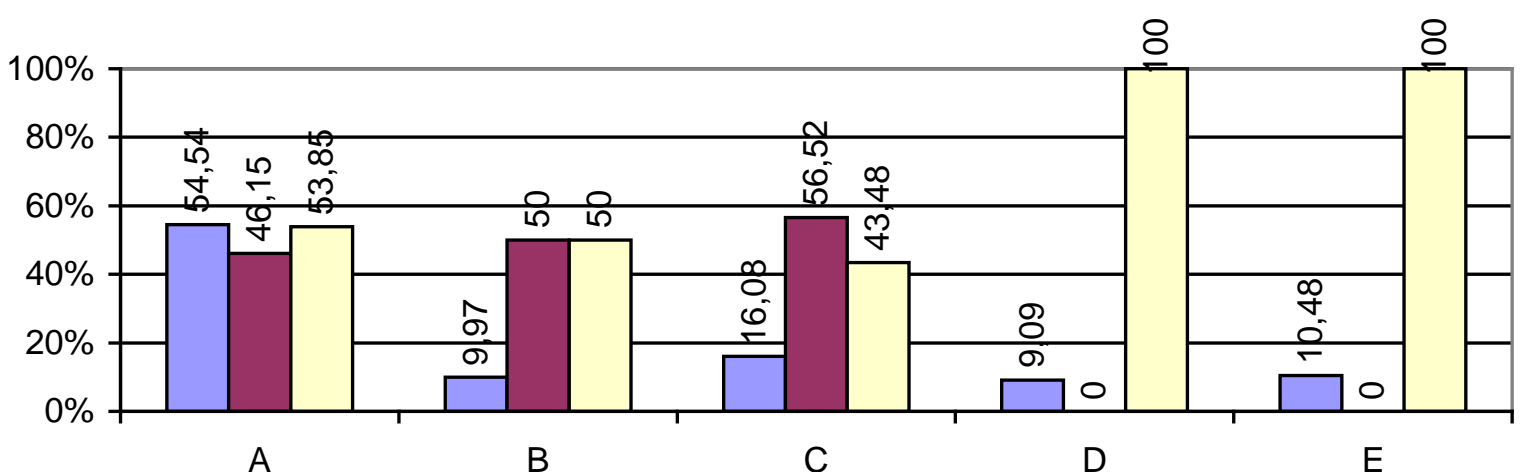

$\square$ Total $\square$ Homens $\square$ Mulheres

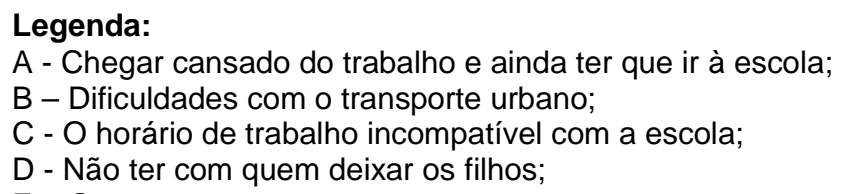

Gráfico 6 - Dificuldades de estudar no noturno

Fonte: dados da pesquisa de campo - CED 07 de Ceilândia - DF/2010 
Em relação às dificuldades apresentadas pelos alunos para estudar no turno noturno, observamos que 8,91\% dos pesquisados, ou seja, 14 alunos, não apresentam qualquer dificuldade de freqüentar a escola no turno noturno. Desses alunos, 14,28\% (2 alunos) são mulheres e 85,72\% (12 alunos) são homens. Os demais, 91,09\% (143 alunos) apresentam dificuldades para estudar no noturno e o principal motivo é a fato de se chegar cansado do trabalho e ainda ter que ir à escola, tanto para homens quanto para mulheres.

Outro questionamento feito aos alunos foi o que os motivou a retomar os estudos. Conforme dados abaixo, podemos verificar as respostas:

Tabela 9

Motivo da retomada dos estudos

\begin{tabular}{|c|c|c|c|c|c|c|c|c|c|c|c|c|}
\hline & \multicolumn{2}{|c|}{ A } & \multicolumn{2}{|c|}{ B } & \multicolumn{2}{|c|}{ C } & \multicolumn{2}{|c|}{ D } & \multicolumn{2}{|r|}{$E$} & \multicolumn{2}{|c|}{$\mathrm{F}$} \\
\hline & $\mathrm{N}^{0}$ & $\%$ & $\mathrm{~N}^{\mathrm{O}}$ & $\%$ & $\mathrm{~N}^{0}$ & $\%$ & $\mathrm{~N}^{0}$ & $\%$ & $\mathrm{~N}^{0}$ & $\%$ & $\mathrm{~N}^{0}$ & $\%$ \\
\hline Total & 116 & 73,88 & 5 & 3,18 & 9 & 5,74 & 8 & 5,10 & 7 & 4,46 & 12 & 7,64 \\
\hline Homens & 47 & 40,51 & 2 & 40,00 & 4 & 44,44 & 3 & 37,5 & 4 & 57,14 & 8 & 66,66 \\
\hline Mulheres & 69 & 59,49 & 3 & 60,00 & 5 & 55,56 & 5 & 62,5 & 3 & 42,86 & 4 & 33,34 \\
\hline
\end{tabular}

\section{Legenda:}

A - Crescimento pessoal;

B - Obter certificado;

C - Promoção no trabalho:

D - Influência da família;

E - Outros;

F - Não respondeu.

Fonte: dados da pesquisa de campo - CED 07 de Ceilândia - DF/2010

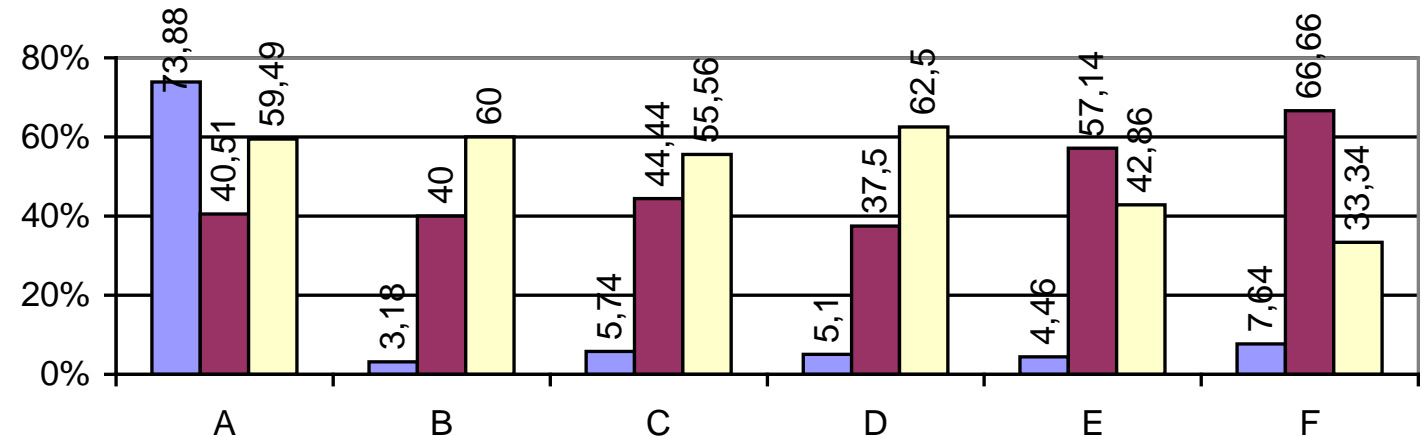

A

B

C

D

E

F

$\square$ Total $\square$ Homens $\square$ Mulheres

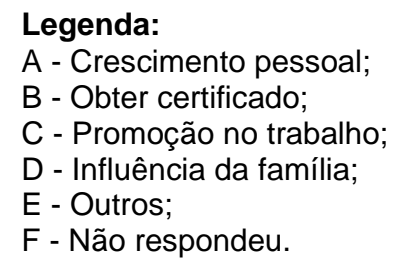

Gráfico 7 - Motivo da retomada dos estudos

Fonte: dados da pesquisa de campo - CED 07 de Ceilândia - DF/2010

Podemos observar que a resposta a esta questão apresentou um fator bastante revelador, uma vez que mostra que os estudantes manifestam desejo por estudar, querem 
realizar-se enquanto pessoas que participam do mundo da informação, conhecimento, ciência e estudos. Para a maioria esmagadora os estudos representam um fator de crescimento e realização pessoal.

Questionados sobre seus empregos, os mais variados cargos e funções foram citados como ocupações e a condição de desempregado também foi bastante mencionada. $\mathrm{E}$ a situação da carteira assinada foi mostrada por eles:

Tabela 10

Carteira assinada

\begin{tabular}{c|r|r|r|r|r|r}
\hline \multirow{2}{*}{ Total } & \multicolumn{2}{|c|}{ Sim } & \multicolumn{2}{c|}{ Não } & \multicolumn{2}{c}{ Não respondeu } \\
\cline { 2 - 7 } & $\mathrm{N}^{0}$ & \multicolumn{1}{c|}{$\%$} & $\mathrm{~N}^{0}$ & \multicolumn{1}{c}{$\%$} & $\mathrm{~N}^{0}$ & \multicolumn{1}{c}{$\%$} \\
\hline Homens & 53 & 33,75 & 100 & 63,70 & 4 & 2,55 \\
\hline Mulheres & 33 & 62,26 & 33 & 33,00 & 2 & 50,00 \\
\hline
\end{tabular}

Fonte: dados da pesquisa de campo - CED 07 de Ceilândia - DF/2010

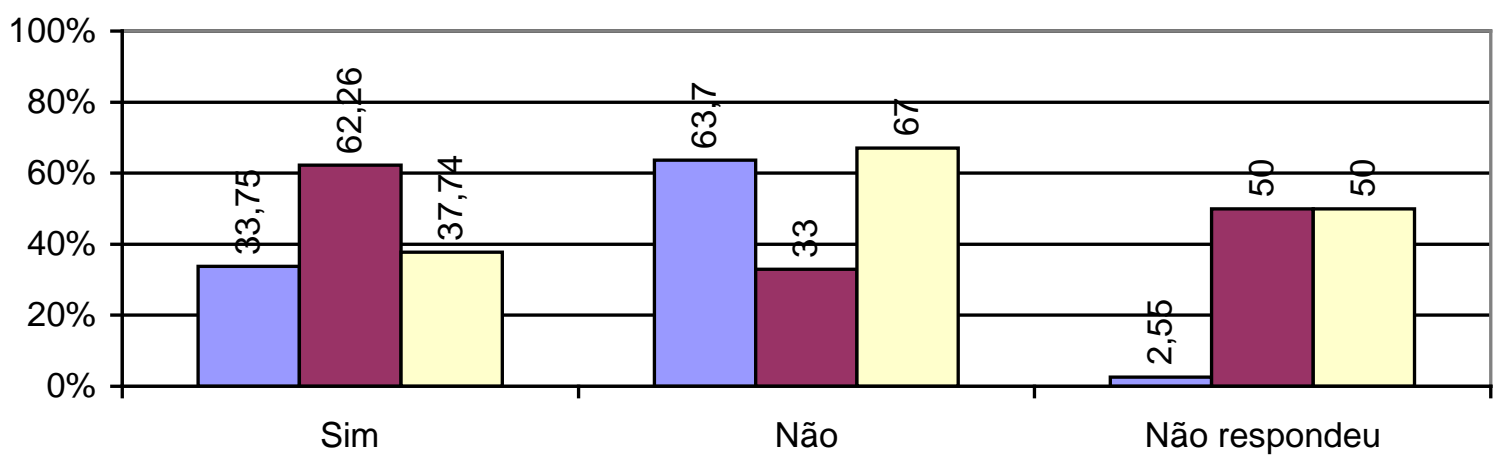

$\square$ Total $\square$ Homens $\square$ Mulheres

Gráfico 8 - Carteira assinada

Fonte: dados da pesquisa de campo - CED 07 de Ceilândia - DF/2010

Vê-se que a maioria dos alunos pesquisados não tem arteira assinada, o que não significa que fiquem sem alguma forma de renda. Muitos desses trabalhadores exercem profissões de maneira informal como diaristas, manicures, cabeleireiras, vendedores em feiras, mas temos também aqueles que tem carteira asinada e exercem profissões como motoristas, empregadas domésticas, diaristas, vigilantes, auxiliares de escritório entre outras. 


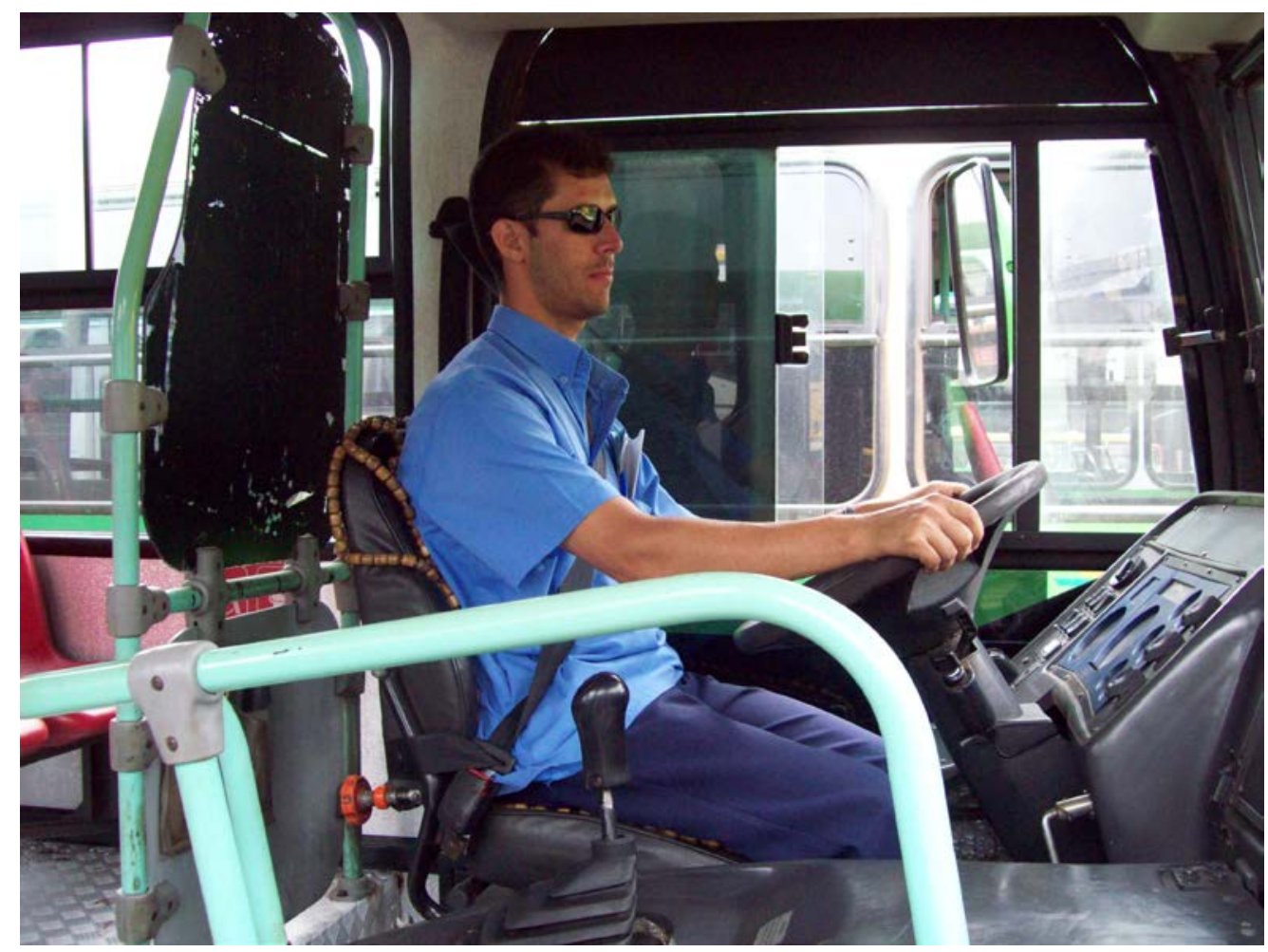

Figura 2: Carlos Henrique (nome fictício), motorista, aluno do $3^{\circ}$ ano. Imagem autorizada.

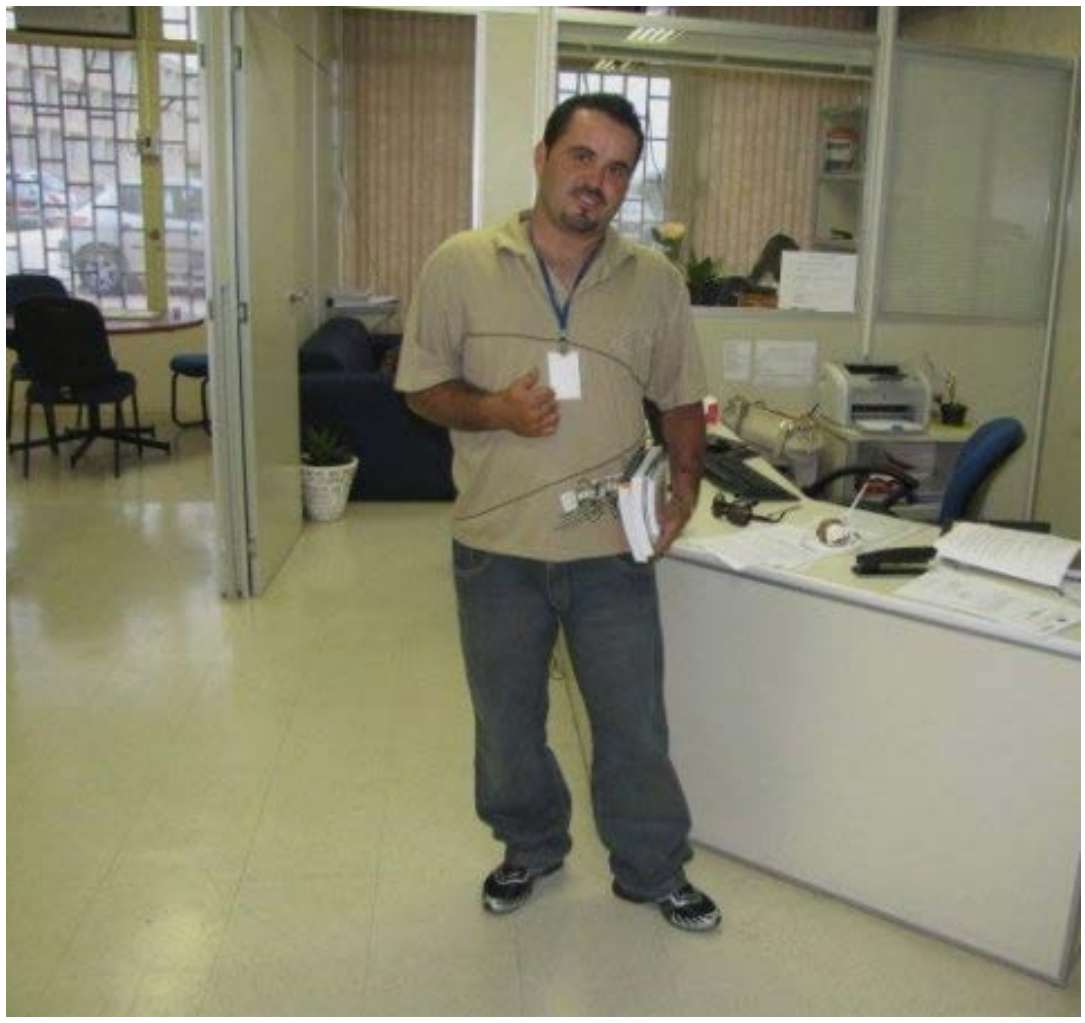

Figura 3: Bruno Santos (Nome fictício), aluno do $3^{\circ}$ ano. Imagem autorizada.

Abaixo temos a resposta quanto à renda do trabalhador/aluno ser o principal sustento da família: 
Renda como principal sustento do domicílio

\begin{tabular}{c|c|c|c|c|c|c|c|c}
\hline \multirow{2}{*}{} & \multicolumn{2}{|c|}{ Sim } & \multicolumn{2}{c|}{ Não } & \multicolumn{2}{c|}{ Não tem salário } & \multicolumn{2}{c}{ Não respondeu } \\
\cline { 2 - 9 } & $\mathrm{N}^{0}$ & $\%$ & $\mathrm{~N}^{0}$ & $\%$ & $\mathrm{~N}^{0}$ & $\%$ & $\mathrm{~N}^{0}$ & $\%$ \\
\hline Total & 52 & 33,12 & 96 & 61,14 & 0 & 0,00 & 9 & 5,74 \\
\hline Homens & 26 & 50,00 & 39 & 40,62 & 0 & 0,00 & 3 & 33,33 \\
\hline Mulheres & 26 & 50,00 & 57 & 59,38 & 0 & 0,00 & 6 & 66,67 \\
\hline
\end{tabular}

Fonte: dados da pesquisa de campo - CED 07 de Ceilândia - DF/2010

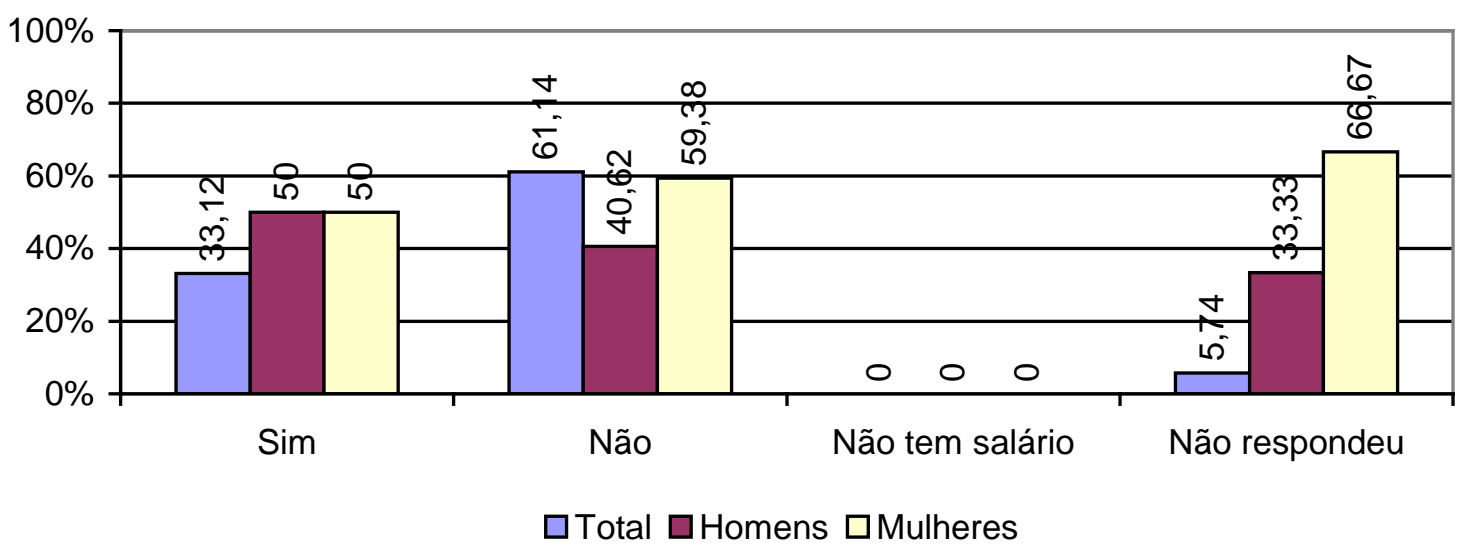

Gráfico 9 - Renda como principal sustento do domicílio

Fonte: dados da pesquisa de campo - CED 07 de Ceilândia - DF/2010

Outro aspecto bastante revelador diz respeito à renda como sustento da família. Observa-se que grande parte das respostas sinaliza para uma tendência de termos alunos cada vez mais novos e que ainda não se responsabilizam pelo sustento familiar, ou seja ainda são filhos e não pais, o que leva a uma observação quanto ao acesso à EJA e a própria finalidade desta modalidade de ensino, uma vez que busca-se atender aos alunos trabalhadores e que por algum motivo ficaram impedidos de concluir seus estudos e não atender a uma parcela de alunos que o Ensino Médio de três anos não foi capaz de absorver.

Questionados sobre o local de trabalho, os mais diferentes lugares foram revelados como: 
Cidade onde trabalha

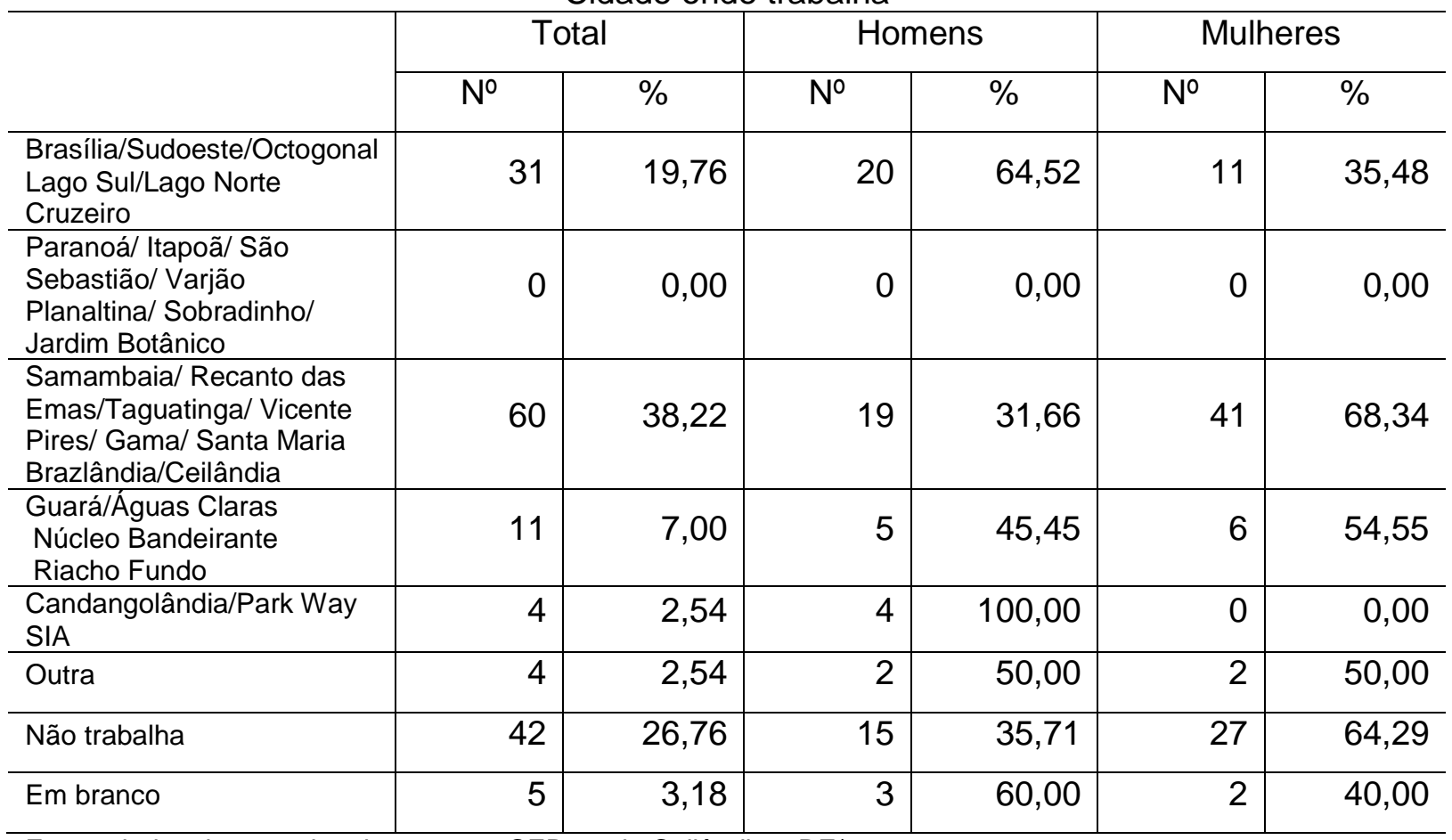

Fonte: dados da pesquisa de campo - CED 07 de Ceilândia - DF/2010

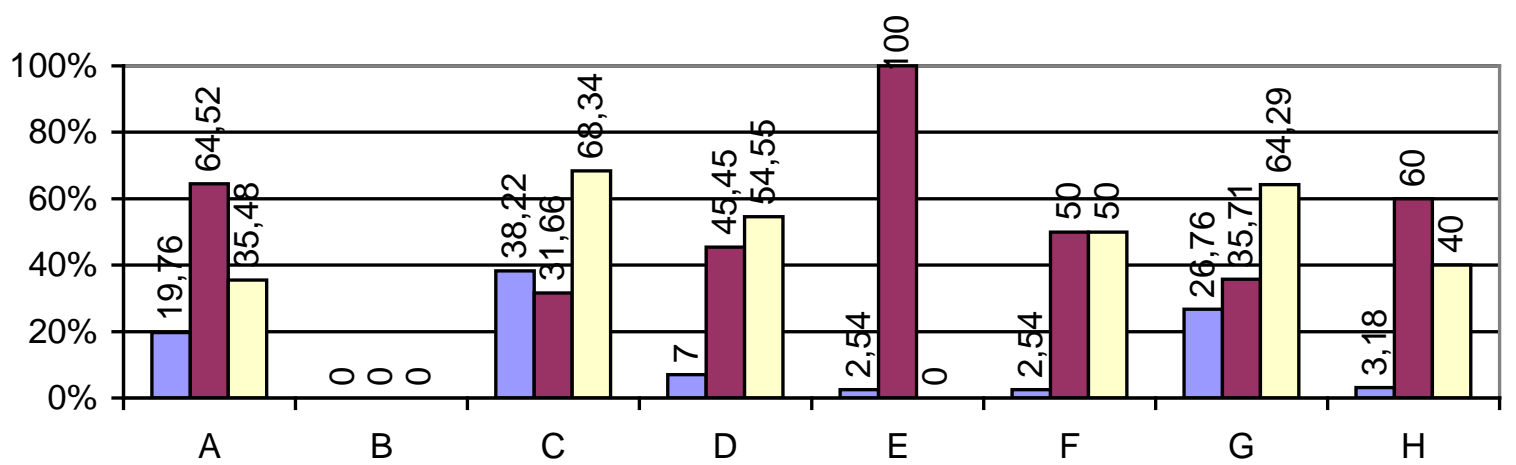

$\square$ Total $\square$ Homens $\square$ Mulheres

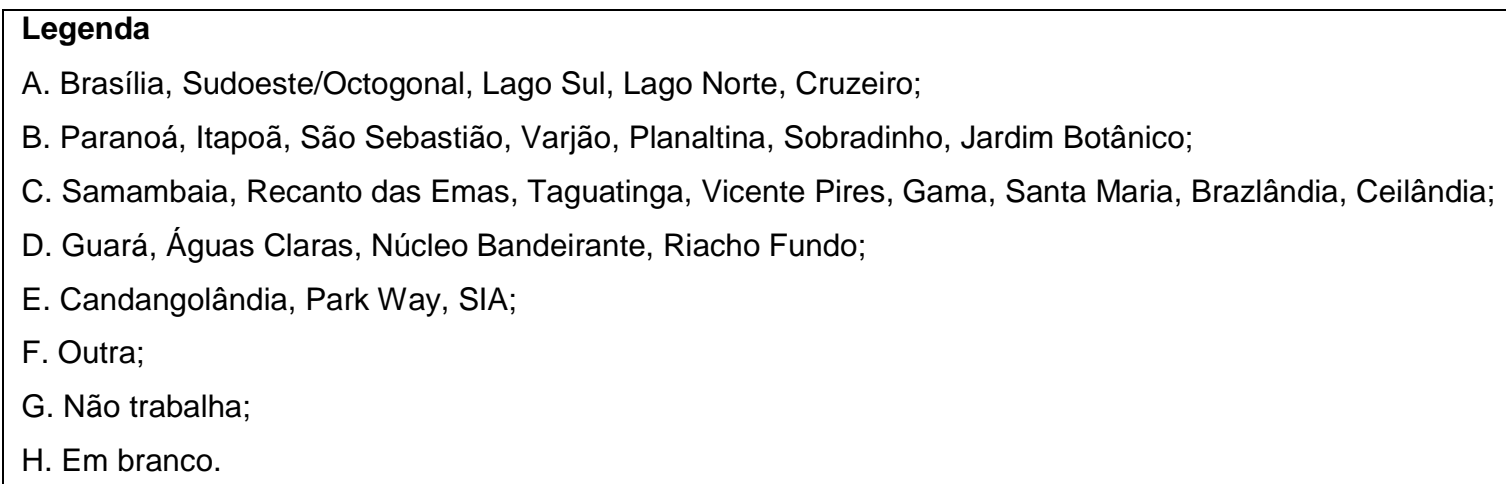

A. Brasília, Sudoeste/Octogonal, Lago Sul, Lago Norte, Cruzeiro;

B. Paranoá, Itapoã, São Sebastião, Varjão, Planaltina, Sobradinho, Jardim Botânico;

C. Samambaia, Recanto das Emas, Taguatinga, Vicente Pires, Gama, Santa Maria, Brazlândia, Ceilândia;

D. Guará, Águas Claras, Núcleo Bandeirante, Riacho Fundo;

E. Candangolândia, Park Way, SIA;

F. Outra;

G. Não trabalha;

H. Em branco.

Gráfico 10 - Cidade onde trabalha

Fonte: dados da pesquisa de campo - CED 07 de Ceilândia - DF/2010 
Dois aspectos importantes são mostrados nesta resposta: observamos que $38,22 \%$ dos nossos alunos trabalham em cidades consideradas próximas de Ceilândia e que $26,76 \%$ deles ainda não trabalham, reforçando mais uma vez a nova característica do alunado da EJA.

E ainda com relação ao trabalho, outro aspecto considerado é em questão a ocupar-se aos finais de semana. Os dados são informados a seguir:

Tabela 13

Trabalho aos finais de semana

\begin{tabular}{c|c|c|c|c|c|c}
\hline \multirow{2}{*}{} & \multicolumn{2}{|c|}{ Sim } & \multicolumn{2}{c|}{ Não } & \multicolumn{2}{c}{ Não respondeu } \\
\cline { 2 - 7 } & $\mathrm{N}^{0}$ & $\%$ & $\mathrm{~N}^{0}$ & $\%$ & $\mathrm{~N}^{0}$ & $\%$ \\
\hline Total & 62 & 39,50 & 83 & 52,86 & 12 & 7,64 \\
\hline Homens & 22 & 35,48 & 41 & 49,40 & 5 & 41,67 \\
\hline Mulheres & 40 & 64,52 & 42 & 50,60 & 7 & 58,33 \\
\hline
\end{tabular}

Fonte: dados da pesquisa de campo - CED 07 de Ceilândia - DF/2010

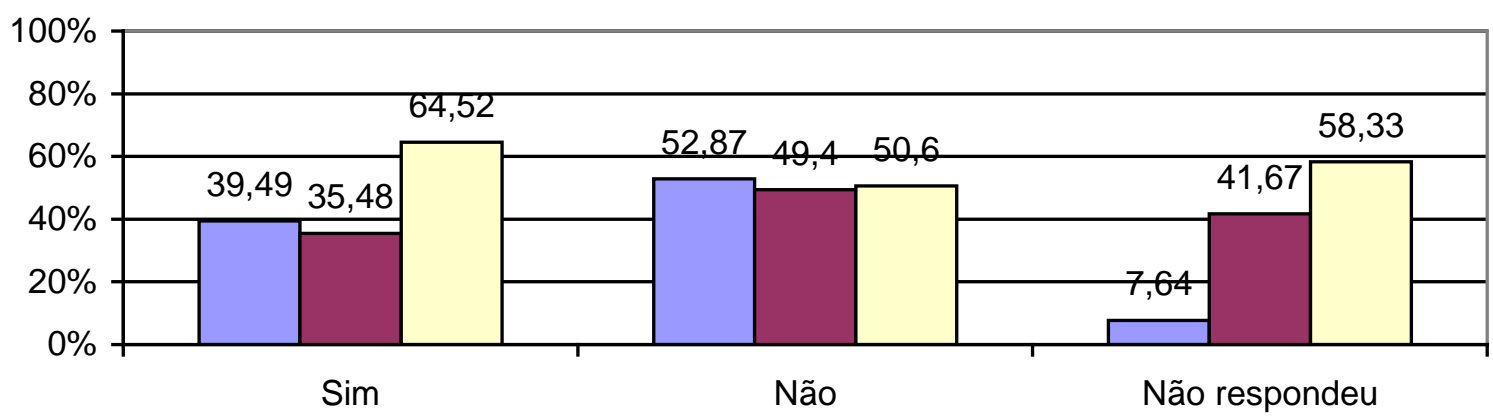

$\square$ Total $\square$ Homens $\square$ Mulheres

Gráfico 11 - Trabalho aos finais de semana

Fonte: dados da pesquisa de campo - CED 07 de Ceilândia - DF/2010

Uma parcela considerável de alunos trabalha nos finais de semana, seja como escala de trabalho da semana ou ainda trabalhar apenas nos finais de semana.

Considerando o acesso à internet e o uso de equipamentos de informática pelos nossos alunos, podemos concluir que grande parte deles tem esse acesso e manuseiam computadores, seja em casa ou em lugares preparados para isso, como Lan Houses, em conformidade com as informações abaixo: 
Tabela 14

Acesso à internet

\begin{tabular}{|c|r|r|r|r|r|r|}
\hline & \multicolumn{2}{|c|}{ Sim } & \multicolumn{2}{c|}{ Não } & \multicolumn{2}{c|}{ Não respondeu } \\
\hline & $N^{0}$ & $\%$ & $N^{0}$ & $\%$ & $N^{0}$ & \multicolumn{1}{c|}{$\%$} \\
\hline Total & 111 & 70,70 & 44 & 28,02 & 2 & 1,28 \\
\hline Homens & 50 & 45,04 & 17 & 38,64 & 1 & 50,00 \\
\hline Mulheres & 61 & 54,96 & 27 & 61,36 & 1 & 50,00 \\
\hline
\end{tabular}

Fonte: dados da pesquisa de campo - CED 07 de Ceilândia - DF/2010

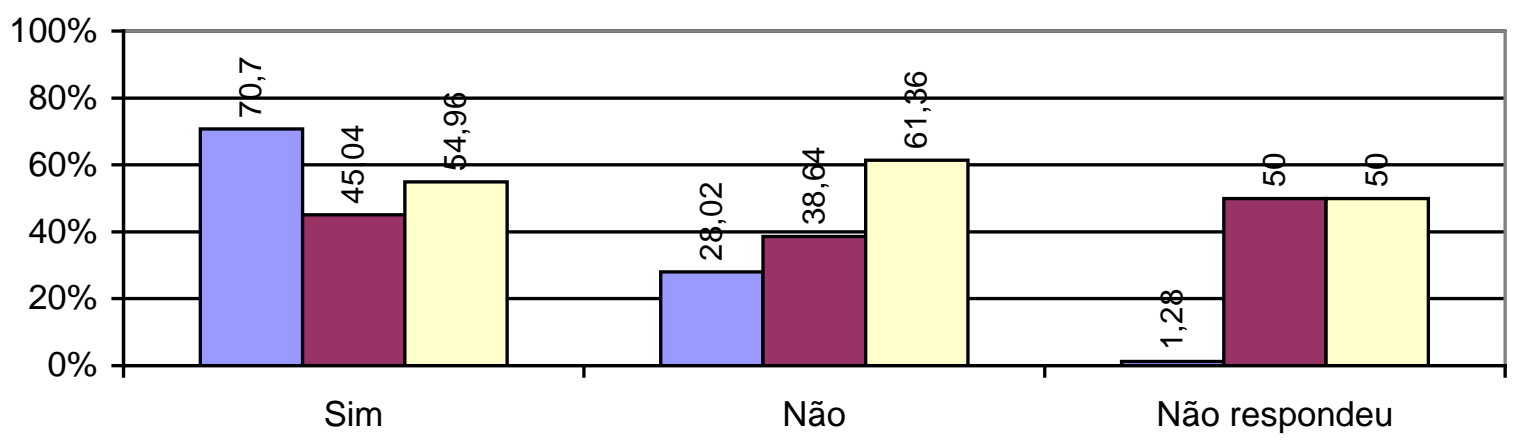

$\square$ Total $\square$ Homens $\square$ Mulheres

Gráfico 12 - Acesso à internet

Fonte: dados da pesquisa de campo - CED 07 de Ceilândia - DF/2010

Para a grande maioria dos alunos pesquisados, o acesso ao sistema de informação através da informática, é facultado, desmistificando a ideia de que as pessoas não se utilizam ou tem dificuldades de manuseio e acesso à internet e computadores.

Em relação à questão sobre o interesse de se fazer EJA à distância, a resposta foi a seguinte:

Tabela 15

Alunos interessados em EAD

\begin{tabular}{|c|c|c|c|c|c|c|}
\hline & \multicolumn{2}{|c|}{ Sim } & \multicolumn{2}{c|}{ Não } & \multicolumn{2}{c|}{ Não respondeu } \\
\hline & $\mathrm{N}^{\mathrm{N}}$ & $\%$ & $\mathrm{~N}^{\mathrm{O}}$ & $\%$ & $\mathrm{~N}^{\mathrm{O}}$ & $\%$ \\
\hline Total & 55 & 35,04 & 96 & 60,60 & 7 & 4,45 \\
\hline Homens & 23 & 41,82 & 43 & 44,80 & 3 & 42,85 \\
\hline Mulheres & 32 & 58,18 & 53 & 55,20 & 4 & 57,15 \\
\hline
\end{tabular}

Fonte: dados da pesquisa de campo - CED 07 de Ceilândia - DF/2010 


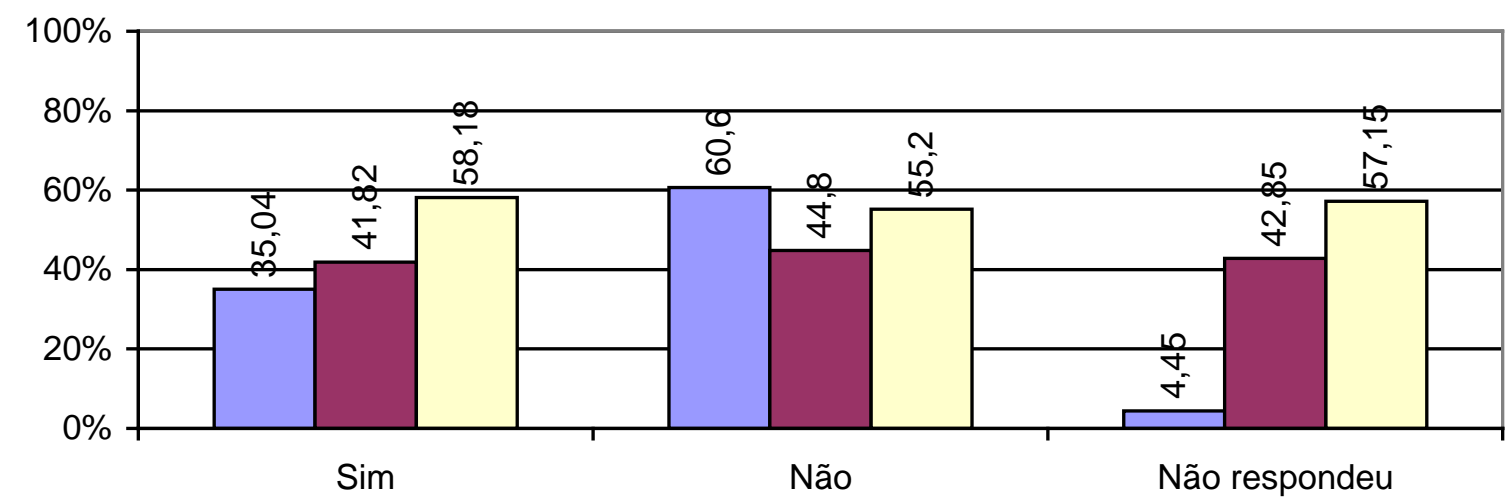

口Total $\square$ Homens $\square$ Mulheres

Gráfico 13 - Alunos interessados em EAD

Fonte: dados da pesquisa de campo - CED 07 de Ceilândia - DF/2010

Nesta questão, observa-se que a resposta negativa em relação ao interesse de se fazer EJA à distância, revela o desinteresse desses estudantes por esta modalidade de ensino. No entanto, podemos inferir que tal resposta se dá pelo fato de se desconhecer ao certo como se dá este tipo de educação, o que será posteriormente analisado.

Nesta primeira análise de dados, podemos observar que nossos alunos são trabalhadores de diversas áreas, com idade a partir de 17 anos e interessados em concluir o Ensino Médio num período de tempo relativamente curto, 1 ano e 6 meses, para EJA. sem que isto necessariamente ocorra na prática. Observando a realidade desde trabalhadores, ficou constatado o alto índice de evasão e a dificuldade de se concluir o Ensino Médio, principalmente devido à dificuldade de se conciliar trabalho e escola. O que nos leva a propor a educação a distância para a EJA, de maneira experimental, no CED 07 de Ceilândia - DF.

Segundo o IBGE, 2007, nos Aspectos Complementares da Educação de Jovens e Adultos, baseado nos dados da Pesquisa Nacional por Amostra de Domicílios - PNAD de 2007, a evasão no Brasil é de 22\% e, no DF, 19\%, para o Ensino Médio em EJA.

\section{EVASÃO}

Apesar de alta, a evasão da EJA no DF é menor que a média nacional, principalmente nos primeiros anos: 
Tabela 16

Índice de evasão no Brasil e no DF

\begin{tabular}{l|c|c}
\hline Segmento & Brasil & DF \\
\hline $1^{\text {a }}$ a $4^{\text {a }}$. Série & $67 \%$ & $43 \%$ \\
\hline $5^{\text {a }}$ a $8^{\text {a }}$. Série & $60 \%$ & $61 \%$ \\
\hline Ensino Médio & $22 \%$ & $19 \%$ \\
\hline
\end{tabular}

Fonte: IBGE/PNAD 2007

No Distrito Federal, os dados da EJA $3^{\circ}$ Segmento, se apresentam da seguinte forma:

Tabela 17

Indicadores de rendimento da EJA no CED 07 de Ceilândia - DF - $3^{\circ}$ segmento

\begin{tabular}{c|c|c|c|c|c}
\hline \multicolumn{3}{c|}{2008} & & \multicolumn{3}{c}{2009} \\
\hline $\begin{array}{c}\text { Taxa de } \\
\text { aprovação }\end{array}$ & $\begin{array}{c}\text { Taxa de } \\
\text { reprovação }\end{array}$ & $\begin{array}{c}\text { Taxa de } \\
\text { abandono }\end{array}$ & $\begin{array}{c}\text { Taxa de } \\
\text { aprovação }\end{array}$ & $\begin{array}{c}\text { Taxa de } \\
\text { reprovação }\end{array}$ & $\begin{array}{c}\text { Taxa de } \\
\text { abandono }\end{array}$ \\
\hline $64,8 \%$ & $31,2 \%$ & $4,0 \%$ & $76,9 \%$ & $20,9 \%$ & $2,2 \%$ \\
\hline
\end{tabular}

Fonte: Sistema de Avaliação do Desempenho das Instituições Educacionais do Sistema de Ensino do Distrito Federal - SIADE - 2009

2.5 Período de execução

Inicio 02/2011 término 07/2011

\section{AMBIENTE INSTITUCIONAL}

De acordo com o levantamento histórico da cidade satélite de Ceilândia, que consta no portal do Distrito Federal - Administração Regional de Ceilândia, em 1969, com apenas nove anos de fundação, Brasília já tinha 79.128 pessoas em situação de favelados, que moravam em 14. 607 barracos, para uma população de 500 mil habitantes em todo o Distrito Federal. Naquele ano, foi realizado em Brasília um seminário sobre problemas sociais no Distrito Federal. O favelamento foi o mais gritante. Reconhecendo a gravidade do problema e suas consequências, o governador Hélio Prates da Silveira (gaúcho de Passo Fundo) solicitou a erradicação das favelas à Secretaria de Serviços Sociais, comandada pelo potiguar Itamar Lopes Cardoso. No mesmo ano, foi criado um grupo de trabalho que mais tarde se transformou em Comissão de Erradicação de Favelas.

Foi criada, então, a Campanha de Erradicação das Invasões, CEI, presidida pela primeira-dama, dona Vera de Almeida Silveira. Em 1971, já estavam demarcados 17.619 lotes, de $10 \times 25$ metros, numa área de $20 \mathrm{Km}^{2}$, depois ampliada para $231,96 \mathrm{Km}^{2}$, pelo Decreto $n^{\circ} 2.842$, de 10 de agosto de 1988, ao norte de Taguatinga nas antigas terras da Fazenda Guariroba, de Luziânia - GO, para a transferência dos moradores das invasões do IAPI; das Vilas Tenório, Esperança, Bernardo Sayão e Colombo; dos morros do Querosene 
e do Urubu; e Curral das Águas e Placa das Mercedes, invasões com mais de 15 mil barracos e mais de 80 mil moradores. A Novacap fez a demarcação em 97 dias, com início em 15 de outubro de 1970.

Em 27 de março de 1971, o governador Hélio Prates lançava a pedra fundamental da nova cidade, no local onde está a Caixa D’água. Às 09 horas daquele sábado, tinha início também o processo de assentamento das vinte primeiras famílias da invasão do IAPI. O Secretário Otomar Lopes Cardoso deu a nova localidade o nome de Ceilândia, inspirado na sigla CEI e na palavra de origem norte-americana "landia", que significa cidade (o sufixo inglês estava na moda). Foi oficiado, na chegada das famílias ao assentamento, um culto ecumênico em ação de graças.

A primeira vez que um ônibus fez a linha Ceilândia - Plano Piloto foi em 28 de março de 1971, um dia após a chegada da primeira família. A primeira coleta de lixo foi feita em 31 de março, sob a coordenação do Serviço de Limpeza Urbana, baseado em Taguatinga.

Em nove meses, a transferência das famílias estava concluída, com as ruas abertas em torno do projeto urbanístico de autoria do arquiteto Ney Gabriel de Souza. Nos primeiros tempos foi um drama. A população carecia de água, de iluminação pública, de transporte coletivo, e lutava contra a poeira, a lama e as enxurradas.

Em 1972, entra em cena uma jovem formada em Serviço Social pela Universidade de Brasília, Maria de Lourdes Abadia Bastos, convidada para trabalhar com a assistente social Julimar Mata Machado. Maria de Lourdes Abadia começou então a trabalhar no Centro de Desenvolvimento Social - CDS, responsável pela integração social dos moradores do novo núcleo habitacional. Logo foi convidada pelo Governador Hélio Prates para assumir a Administração de Ceilândia. Abadia continuou na Administração, nos Governos seguintes, sendo a responsável pelas bases da Ceilândia moderna.

Em 27 de junho de 1975, o Decreto n. ${ }^{\circ} 2.842$ definia a área dos setores $\mathrm{M}$ e $\mathrm{N}$ de Taguatinga, Dois dias depois, o Decreto n. 2.943 criava a Administração de Ceilândia, vinculada a Administração Regional de Taguatinga. Em 25 de outubro de 1989, a Lei 11.921 criava a nova Região Administrativa do Distrito Federal, que virava, assim, a nova cidadesatélite de Ceilândia. O aniversário de Ceilândia é comemorado no dia 27 de março, por força do Decreto n. ${ }^{\circ}$ 10.348, de 28 de abril de 1987.

É no cenário da Ceilândia de 1974 que surge o CED 07. Localizado à QNN 13, Área Especial - A, Ceilândia Norte-DF, o Centro Educacional 07 foi fundado em 17 de abril de 1974, com o nome de Centro de Ensino 03 Ceilândia. Com uma área de 61.943,32 metros quadrados, sendo 4.202,29 metros quadrados de área construída, o CED 07 foi criado para atender à demanda de crianças e adolescentes que vieram com seus pais das invasões, 
com a já citada Campanha de Erradicação de Invasões. Em 1980, o nome da instituição passou a ser Centro Educacional 07 de Ceilândia, o qual mantém até os dias de hoje.

Caracterizada pela carência de recursos financeiros, a comunidade da Ceilândia sul apresenta-se com um perfil socioeconômico em que grande parte de seus moradores carecem de eventos e espaços culturais e de lazer. Estes formam a maioria dos alunos do CED 07. Temos alunos vindos de Águas Lindas de Goiás, Santa Maria e Samambaia. Existe uma variedade considerável de condições socio-culturais dentre os alunos do CED 07 de Ceilândia, onde uma parcela da comunidade possui uma renda per capta muito baixa, deste a maioria recebe uma ajuda do governo como o "Renda Minha" (Programa de governo que prevê o recebimento de uma bolsa-auxílio para a família por cada filho matriculado na escola), outra parcela já possui um poder aquisitivo melhor sendo que alguns são filhos ou parentes de funcionários da própria escola e também filhos de funcionários públicos de outros locais, como filhos de professor, bombeiro, policial militar dentre outros.

Muitos dos pais são bastante exigentes com a educação do filho, bastante críticos e estão sempre questionando algumas ações que são desenvolvidas na escola, assim como também participam e ajudam na organização dos eventos. Mas a grande maioria acaba esquecendo a responsabilidade da família e deixam de acompanhar os filhos o que acaba acarretando em problemas de cunho pedagógico no sentido de dificultar o processo ensinoaprendizagem, quanto de cunho pessoal trazendo problemas disciplinares que tem repercussão no trabalho desenvolvido dentro da escola e também problemas familiares.

Um dos problemas que o CED 07 de Ceilândia enfrenta é a questão da segurança, onde na saída dos turnos ficam nos arredores da escola elementos estranhos que abordam alunos e alunas, muitas das vezes para assediá-los e algumas das vezes acontecem assaltos, roubos de celulares, tênis e outros objetos pessoais.

Atualmente a escola tem passado por várias reformas na busca por criar condições favoráveis ao processo educativo. Hoje recebe cerca de 2551 alunos a partir de 10 anos de idade, em 30 turmas desde as séries finais do Ensino Fundamental até o Ensino Médio e o $3^{\circ}$ Segmento da EJA. Destes números temos 557 alunos da EJA - $3^{\circ}$. Segmento $\left(1^{\circ}, 2^{\circ}\right.$, e $3^{\circ}$. Semestre), com carga horária de $400 \mathrm{~h}$ semestrais. A proposta Pedagógica da escola está adequada às Diretrizes Curriculares Nacionais e à Resolução 2/98 do Conselho de Educação do DF, considerando as Diretrizes do Currículo e a necessidade de tornar a educação mais eficiente, dinâmica e adequada aos novos tempos. Visando atender as dificuldades de aprendizagem dos educandos que formam o universo do C.E.D 07 de Ceilândia, a escola implementa projetos que norteiam os trabalhos dos educadores e dos alunos, fazendo-se necessário para alcançarmos o objetivo maior que é a preparação primordial do aluno para vida e o pleno exercício da cidadania. 
A escola recebe alunos oriundos dos setores QNQ, QNR e Chácaras, segundo ficha SOME da secretaria, preenchida no ato da matricula, os quais são transportados nos ônibus cedidos pela Secretaria de Educação do Distrito Federal. As faixas etárias de 10 a 17 anos apresentam maior índice de alunos indisciplinados (200 alunos por ano- informação do SOE da I.E), e alguns envolvidos com drogas.

Os alunos da EJA trabalham e muitas vezes não conseguem conciliar as duas atividades: trabalho e escola. E o que temos visto é que muitos optam pelo trabalho em detrimento à escola. Embora a escola conte com um corpo docente completo e especializado, que objetiva, através de ações conjuntas com a direção da escola, implementar projetos interdisciplinares para manter o aluno na escola, como a implementação de projetos na parte diversificada, tais como Educação Sexual, Educação Ambiental, Educação Alimentar e o projeto da I.E (preparação dos alunos para realização das provas do ENEM), os aspectos formativos e qualitativo em todos os turnos e também para o noturno. No entanto, não tendo obtido grande êxito, visto o número de evasão a cada ano.

\section{4- JUSTIFICATIVA}

No Distrito Federal a Educação de Jovens e Adultos - EJA, (segmento de ensino que recebe os jovens e adultos que não completaram os anos da educação básica em idade apropriada e querem voltar a estudar) é oferecida a todo cidadão que queira concluir o ensino fundamental e/ou médio em um período mais curto do que o convencional. Contudo o ingresso desses alunos nessa modalidade de ensino não tem garantido a conclusão no prazo estimado. São pais e mães de família, trabalhadores formais, informais ou desempregados que tem em comum o passado marcado pela pobreza e/ou o abandono dos bancos escolares.

No inicio do semestre as salas estão cheias de educandos, mas no decorrer do tempo vão esvaziando. Este fenômeno, caracterizado como evasão escolar, atinge todo o Brasil e, no Distrito Federal não seria diferente, visto os dados apresentados pelo Instituto Brasileiro de Geografia e Estatística, IBGE de 2009. No Brasil, a média de evasão para a EJA é de $42 \%$ enquanto que no DF é de $32 \%$, conforme a pesquisa.

Assim como ocorre em todo o DF, a evasão escolar acontece no Centro Educacional 07 de Ceilândia, sobretudo em EJA, com índice de 46\% em 2009, em virtude dos alunos serem trabalhadores/as e/ou donos/as de casa, enfrentando dupla jornada de trabalho e, ainda por, não conseguirem conciliar o horário do trabalho com o da escola 
Um fator que agrava essa situação é a exigência formal da freqüência regular do aluno e seu peso sobre sua aprovação ou reprovação, segundo parecer n 325/2008 - CEDF (Conselho Educação do Distrito Federal).

Desta forma, procurando soluções para conter a evasão na EJA - Ensino Médio, propomos, como Política Pública a Educação à Distância para esta modalidade a ser implementado de forma experimental no CED 07 de Ceilândia do Distrito Federal, por entendermos que esta forma de ensino é a mais adequada para atender à demanda de estudantes que buscam a escolarização e não conseguem conciliar seus afazeres com as necessidades escolares.

Como proposta de implementação do sistema à distância para a educação de jovens e adultos, tomamos a resolução $N^{0}$ 3, de 15 de junho de 2010 do Conselho Nacional de Educação - Câmara de Educação Básica, como parâmetro para a execução deste projeto que institui as Diretrizes Operacionais para a Educação de Jovens e Adultos, descritas a seguir, quanto a duração dos cursos de 1200 horas para o Ensino Médio, idade mínima de 18 anos para ingresso e certificação da EJA em EAD, garantindo um sistema Público de Educação Básica, enquanto política pública de gestão democrática e contemplando a diversidades de sujeitos aprendizes. Ainda, de acordo com a Resolução, a EAD na EJA deve ser desenvolvida em comunidade de aprendizagem em rede, utilizando-se das Tecnologias de Informação e Comunicação TIC, sem dispensar o ambiente escolar presencial, organizado para as práticas educacionais de formação profissional. Outro aspecto considerado diz respeito aos professores que deverão ser licenciados na disciplina e deverão atender até 120 alunos em uma jornada de 40 horas de trabalho, passando por formação inicial e continuada para lidar com a EAD. Serão fornecidos livros didáticos e de literatura, bem como acesso à biblioteca de apoio pedagógico para a prática de $E A D$, bem como garantir o acesso dos estudantes e professores a todos os meios possíveis de informatização e comunicação como biblioteca, rádio, televisão e computadores ligados à internet. A Resolução considera, ainda, que o processo avaliativo deverá ser contínuo, processual e abrangente, com auto avaliação e avaliação em grupo, presenciais. Orienta ainda que haja avaliação. A EAD em EJA - Ensino Médio deverá, ainda, reconhecer e aceitar a transferência dos cursos de EJA presenciais para os oferecidos pelo sistema EAD. A Instituição que ofertar EJA em EAD deverá ser autorizada, credenciada e avaliada pelo poder público para seu efetivo funcionamento. Tomamos, assim, esses parâmetros como os norteadores para o desenvolvimento das atividades propostas pelo projeto. 


\section{5- OBJETIVOS}

\section{1- Objetivo Geral:}

Promover o implantação experimental do processo ensino-aprendizagem, para a EJA com a modalidade de Educação a distância, atendendo as necessidades dos jovens e adultos trabalhadores no CED 07 Ceilândia, no Distrito Federal, na Rede Pública de Ensino do DF, como fomentação à implantação da Resolução $n^{\circ} 3$ de junho de 2010 do Conselho Nacional de Educação - Câmara de Educação Básica.

\section{2- Objetivos específicos:}

- Contribuir para a socialização do conhecimento aliada à modernização tecnológica condizentes com as exigências da sociedade contemporânea ;

- Contribuir para a universalização da educação básica entre os jovens e adultos trabalhadores garantindo o acesso e a permanência.

- Contribuir para a melhoria da qualidade do ensino através de metodologias que associem teorias e prática e aproveitem a formação e a experiência, do jovem e do adulto.

- Promover o princípio do direito de aprender, ampliando conhecimentos ao longo da vida através dos meios de comunicação da informação;

- Contribuir com a educação inclusiva pautada nos direitos humanos e no reconhecimento da diversidade;

- Assegurar a ampliação do direito à educação básica pública, gratuita e de qualidade, pela universalização do ensino médio através da tecnologia;

- Ampliar mecanismos de divulgação e conscientização do direito à educação de jovens e adultos em EAD;

- Sensibilizar o corpo docente e discente do CED 07 de Ceilândia para a implementação da EAD em EJA - Ensino Médio, através do esclarecimento sobre o funcionamento e prática do processo e Educação à Distância;

- Estruturar o CED 07 como pólo de apoio pedagógico com acesso aos mais variados mecanismos de comunicação e informatização, como computadores com acesso à internet, televisores, rádio e biblioteca.

\section{6 - ATIVIDADES/RESPONSABILIDADES}

O projeto será executado no decorrer do semestre letivo, em fase experimental, da seguinte forma:

Entrega do cronograma escolar;

Aula inicial de forma presencial, para informar como funcionará o curso, e entrega do material escolar, como livros, apostilas e o portal que vai ser usado. 
Laboratório de informática da escola abrirá no período diurno e noturno para os alunos da EJA utilizarem.

Datas para tirarem dúvidas conforme disponibilidade do aluno

Datas previstas para avaliação escrita presencial

Serão coordenadas pela direção, pela secretaria escolar pelos professores, coordenador local.

\section{7 - CRONOGRAMA}

O projeto será executado no decorrer do $1^{\circ}$ semestre letivo de 2011 , em fase experimental, onde:

\begin{tabular}{l|l}
\hline PERÍODO & ATIVIDADES: \\
\hline Janeiro & Identificação dos alunos matriculados na rede pública \\
\hline Fevereiro & $\begin{array}{l}\text { Seleção da turma para aplicação do projeto; } \\
\text { Início das aulas: Início das atividades pedagógicas } \\
\text { para a turma - Aula inaugural; }\end{array}$ \\
\hline Fevereiro a Julho & Período de aulas e avaliações \\
\hline Julho & Período de avaliação dos alunos \\
\hline Agosto & Avaliação da viabilidade do projeto \\
\hline
\end{tabular}

\section{8 - PARCEIROS}

O projeto terá como desafio a conquista de parceiros que somem esforços para a sua realização e implementação, como:

Escola de Aperfeiçoamento de Professores (EAPE);

Programa Universidade Aberta do Brasil (UAB);

Universidade de Brasília (UNB).

\section{9- ORÇAMENTO}

A instituição escolar iniciou este ano o projeto inclusão digital, no qual está oferecendo cursos aos professores e alunos, portanto todo orçamento do projeto já está vinculado a escola e aos órgãos competentes públicos. O custo operacional de manutenção das máquinas e atualizações de programas e tutores fica orçado em $\mathrm{R} \$ 3.000,00$ (três mil reais mensais), custeado pela APAM. Fica prevista também a adequação da biblioteca, de salas com aparelhos de televisão e rádio, já existentes na escola. 


\section{0- ACOMPANHAMENTO}

Níveis de acompanhamento: Coordenação pedagógica (avaliação processual);

Execução: professores licenciados por disciplina;

Avaliação final de curso: aplicada pelo professor de forma presencial e atendendo ao especificado pela Resolução;

Avaliação diagnóstica para alunos e professores quanto a viabilidade do projeto no CED 07 de Ceilândia. 


\section{1 - REFERÊNCIAS}

ANGELIM, Maria Luiza. Capítulo IV: "Evoluindo e Gerando Conhecimento",Educação Superior a Distância - Comunidade de Trabalho e Aprendizagem em Rede (CTAR) de autoria de Rodrigues, M.A, 2009. http://forumeja.org.br/df/

ARROYO, Miguel. Educação de Jovens e Adultos - um campo de direitos e de responsabilidade pública in: SOARES, Let ali (orgs.) Diálogos na educação de jovens e adultos. Belo Horizonte: Autêntica, 2005.

BARRETO, Vera. Paulo Freire para educadores. São Paulo: Arte Ciência, 1998.

DI PIERRO, M.C. Notas sobre a redefinição da identidade e das políticas públicas de educação de jovens e adultos no Brasil Educação e Sociedade. vol. 26 no.92 Campinas Oct. 2005.

FREIRE, Paulo. Educação como prática da liberdade. 26 ed. Rio de Janeiro-RJ: Paz e Terra, 1994.

IBGE - Aspectos Complementares da Educação de Jovens e Adultos e Educação Profissional 2009

PNAD - Pesquisa Nacional por amostra de Domicílios, sobre educação profissional e aspectos complementares da EJA - Ministério da Educação, 2007.

Resolução no 3, de 15 de Junho de 2010 do Ministério da Educação, Conselho Nacional de Educação, Câmara de Educação Básica.

SIADE - Sistema de Avaliação do Desempenho das Instituições Educacionais do Sistema de ensino do distrito Federal - 2009. 


\section{ANEXOS}

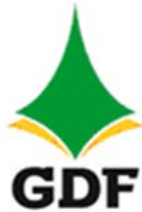

\section{GOVERNO DO DISTRITO FEDERAL SECRETARIA DE ESTADO DE EDUCAÇÃO DIRETORIA REGIONAL DE ENSINO DE CEILÂNDIA Centro Educacional 07 da Ceilândia}

Questionário diagnóstico dos Jovens e Adultos do Centro Educacional 07 da Ceilândia

Caro(@) aluno (@),

O presente questionário tem como objetivo diagnosticar as características e alguns fatores importantes para o processo de ensinar e aprender. Nas questões de múltipla escolha, por favor, circule, em cima da letra, somente uma alternativa.

Obrigad@pela participação!

\section{1- Sexo:}
a) Feminino.
b) Masculino.

2- Qual a sua naturalidade? (Cidade e estado)

3 - Qual é a sua idade?
a) De 17 a 24 anos.
b) De 25 a 32 anos.
c) De 33 a 40 anos.
d) De 41 a 48 anos.
e)Mais de 49.

4 - Tem moradia própria?
.a) $\operatorname{Sim}$
b) não
c) outros. Qual?

5- Você já interrompeu seus estudos por algum motivo?
a) Sim. Quantas vezes foi e voltou?
b) Não.

6- Qual o motivo que o(a) levou a interromper os estudos?
a) Família.
b) Não conseguiu vaga na escola.
c) Trabalho.
d) Falta de dinheiro.
e) Outro. Qual?

7- Por quanto tempo você ficou sem estudar?
a)Por meses.
b) Por 1 a 2 anos.
c) Por 3 a 5 anos

d) Por 5 a 9 anos.

e) Por mais de 10 anos.

8- Qual é a maior dificuldade em estudar no turno noturno?

a) Chega cansado do trabalho e ainda tem que ir à escola.

b) O transporte urbano. $\quad$ c) O horário de trabalho. $\quad$ d) Não tem com quem deixar os filhos.

e) Outros. Qual?

9- Por que você decidiu retomar os estudos? 


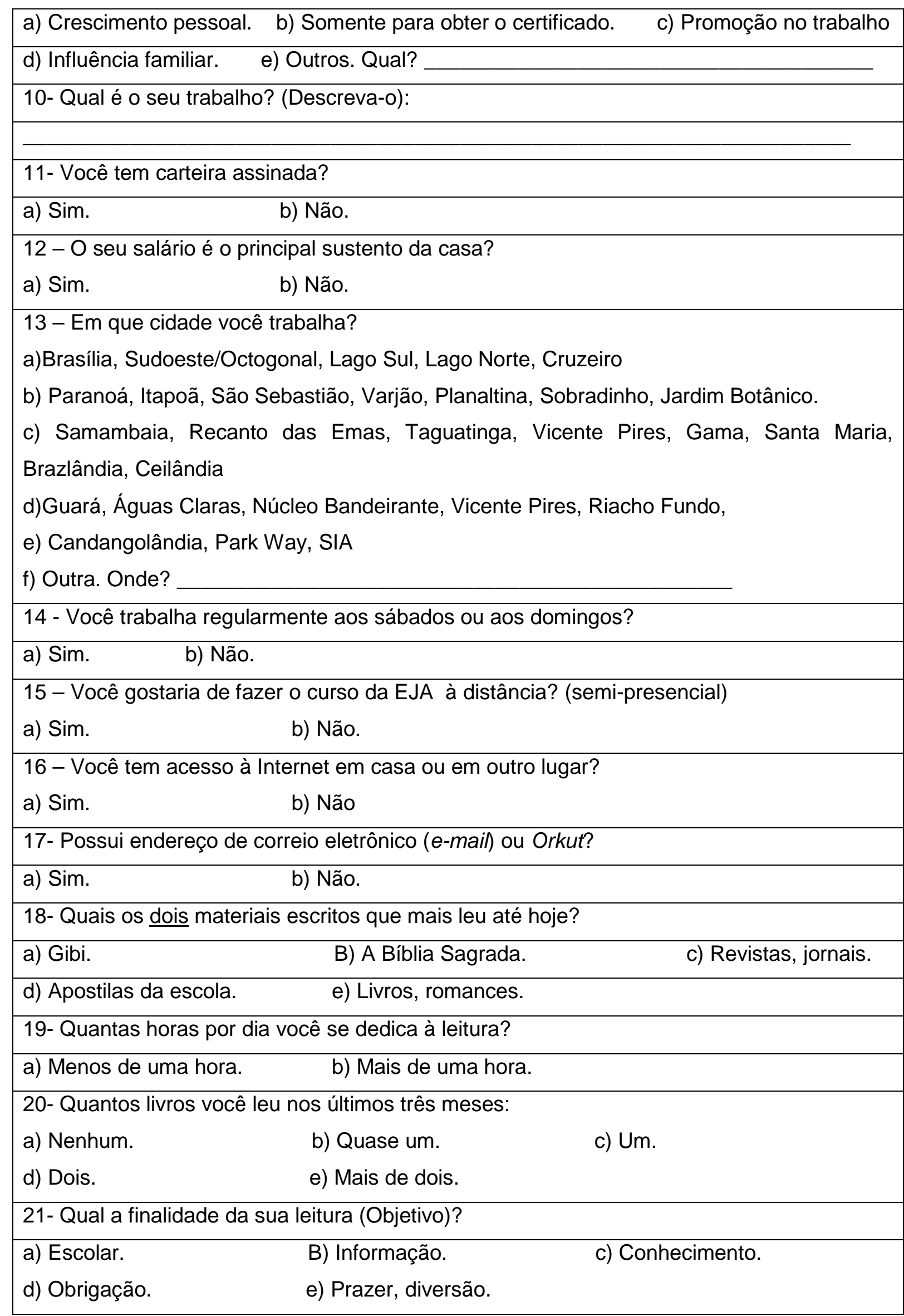

